\title{
Endoscopic microscopy
}

\author{
Konstantin Sokolov ${ }^{\mathrm{a}}$, Kung-Bin Sung ${ }^{\mathrm{b}}$, Tom Collier ${ }^{\mathrm{b}}$, Anne Clark ${ }^{\mathrm{b}}$, Dizem Arifler ${ }^{\mathrm{b}}$, Alicia Lacy ${ }^{\mathrm{b}}$, \\ Michael Descour ${ }^{\mathrm{c}}$ and Rebecca Richards-Kortum ${ }^{\mathrm{b}, *}$ \\ ${ }^{a}$ Department of Imaging Physics, UT M.D. Anderson Cancer Center, Houston, TX 77030, USA \\ ${ }^{\mathrm{b}}$ Department of Biomedical Engineering, University of Texas, Austin, TX 78712, USA \\ ${ }^{\mathrm{c}}$ Optical Sciences Center, University of Arizona, Tucson, Arizona 85721, USA
}

\begin{abstract}
In vivo endoscopic optical microscopy provides a tool to assess tissue architecture and morphology with contrast and resolution similar to that provided by standard histopathology - without need for physical tissue removal. In this article, we focus on optical imaging technologies that have the potential to dramatically improve the detection, prevention, and therapy of epithelial cancers. Epithelial pre-cancers and cancers are associated with a variety of morphologic, architectural, and molecular changes, which currently can be assessed only through invasive, painful biopsy. Optical imaging is ideally suited to detecting cancer-related alterations because it can detect biochemical and morphologic alterations with sub-cellular resolution throughout the entire epithelial thickness. Optical techniques can be implemented non-invasively, in real time, and at low cost to survey the tissue surface at risk. Our manuscript focuses primarily on modalities that currently are the most developed: reflectance confocal microscopy (RCM) and optical coherence tomography (OCT). However, recent advances in fluorescence-based endoscopic microscopy also are reviewed briefly. We discuss the basic principles of these emerging technologies and their current and potential applications in early cancer detection. We also present research activities focused on development of exogenous contrast agents that can enhance the morphological features important for cancer detection and that have the potential to allow vital molecular imaging of cancer-related biomarkers. In conclusion, we discuss future improvements to the technology needed to develop robust clinical devices.
\end{abstract}

\section{Introduction}

In the developed world, cancer is the second leading cause of death, exceeded only by heart disease. Despite major advances in cancer treatment, five-year survival rates have increased only moderately over the past 30 years for most cancers. As an example, overall five-year-survival rates for patients with advancedstage cancers of the oral cavity have remained at 30$40 \%$ at best. In addition, most oral cavity cancer patients present with tumors at advanced stages, when treatment is more difficult, more expensive, and less successful compared to earlier interventions. In all cancers, patients with early stage disease have significantly better chances for cure and less treatment-associated morbidity. Early detection of pre-neoplastic and neo-

${ }^{*}$ Corresponding author. Department of Biomedical Engineering, ENS 8, University of Texas, Austin, TX 78712, USA. Tel.: +1 512 471 2104; Fax: +1 512475 8854; E-mail: kortum@mail.utexas.edu. plastic changes may be our best method to improve patient quality of life and survival rates.

The majority of cancers originate in epithelial tissues and are preceded by curable pre-neoplastic lesions. However, early diagnosis of epithelial pre-cancers has eluded us for several possible reasons: (1) Inexperienced practitioners often fail to recognize the subtle clinical changes indicative of early neoplastic transformation; (2) It is difficult to distinguish pre-malignant lesions from more common benign inflammatory conditions in the general population; (3) Practitioners and patients often are reluctant to perform invasive biopsies or repeated biopsies of epithelial lesions where the expected yield is low; and (4) In high-risk patients, often the entire epithelium is potentially pre-malignant, making it difficult even for experienced clinicians to know when and where to biopsy. Thus, technological advancements that improve the ability of general practitioners to recognize and accurately diagnose precancerous lesions in epithelial tissue are desperately 
needed. In this article, we review new developments in optical endoscopic microscopy that have the potential to improve the detection of these lesions.

Epithelial pre-cancers and cancers are associated with a variety of morphologic and architectural alterations, including larger nuclear size, increased nuclear/cytoplasmic ratio, hyperchromasia and pleomorphism [1]. In current clinical practice, these changes can be assessed only through invasive, painful biopsy. Biopsies are fixed, sectioned, stained, and examined under light microscopy to assess the biochemical and architectural features associated with cancer and its precursors. This process is invasive, time consuming, and expensive. Currently, there are no good clinical tools to definitively diagnose pre-cancerous changes without biopsy and subsequent histologic analysis.

Recently, a number of promising new optical imaging technologies have emerged as potential tools for detecting pre-cancerous changes in vivo without the need for biopsy. Optical imaging is suited ideally to detecting cancer-related alterations, because it can non-invasively detect biochemical and morphologic alterations with sub-cellular resolution and in real-time throughout the entire epithelial thickness. Also, optical methods are especially suited to detecting epithelial disease because the penetration depth of light inside human tissue (about $1.5 \mathrm{~mm}$ ) is sufficient to analyze the whole epithelial thickness. The low cost of building these systems and advances in optics miniaturization combine with these characteristics to make optical imaging an ideal candidate for endoscopic implementation.

In this article, we review recent developments in photonic technology that provide the ability to noninvasively image epithelial tissue with high spatial resolution in vivo. We focus on optical imaging technologies that have the potential to dramatically improve the detection, prevention, and therapy of epithelial cancers. The largest body of experimental data currently is available for reflectance confocal microscopy (RCM) and optical coherence tomography (OCT), which imagebackscattered light [2,3]. Recently, microendoscopes for in vivo high resolution imaging have been developed for both RCM [4] and OCT [5]. Thus, our report is focused primarily on these two techniques. However, recent advances in development of fluorescence based endoscopic microscopy also are reviewed briefly. We begin by discussing the basic principles of these emerging technologies and their current and potential applications in early cancer detection in the skin, cervix, esophagus, and oral cavity. Limitations of these tech- nologies naturally lead to consideration of current research in disease markers that can be assessed using optical methods. We give a brief description of cancerrelated biomarkers and describe intrinsic sources of contrast associated with these biomarkers. However, the intrinsic sources of contrast in human tissue usually provide signals with low intensity and very limited molecular-specific information. We describe research activities focused on development of exogenous contrast agents that can enhance the morphological features important for cancer detection and can enable imaging of cancer-related molecular alterations. We conclude by discussing future improvements needed to advance optical endoscopic microscopes to widespread clinical use for pre-cancer detection.

\section{Basic principles of RCM and OCT}

The gold standard for cancer detection in epithelial tissues is the histological analysis of nuclear features from excised and processed tissue. A non-invasive alternative is to image cells in vivo using reflected light from within the tissue. This approach is similar to histological analysis of biopsies with the added advantage that 3D sub-cellular resolution can be achieved in near real time without removal of tissue. Changes in the index of refraction provide contrast to recognize intracellular details. Detection of increased nuclear size, nuclear to cytoplasmic ratio, and nuclear texture using optical endoscopic microscopy has the potential to yield sufficient information to diagnose neoplasia in vivo without tissue removal in a manner similar to histology. RCM and OCT are two promising optical technologies to image these features in vivo. In the next section, we review the basic physical principles of these technologies.

\subsection{In vivo reflectance confocal microscopy}

\subsubsection{Non-fiber-based reflectance confocal microscopy}

In concept, in vivo reflectance confocal imaging is similar to histologic analysis of biopsies, except that 3D sub-cellular resolution is achieved without removing tissue, and contrast is provided without stains. The optical sectioning principle of confocal imaging is illustrated in Fig. 1. The illumination light (solid line) passes through a beam splitter and is focused by a lens to a point within the sample. Since tissue is highly scattering, some illumination light is reflected from all 


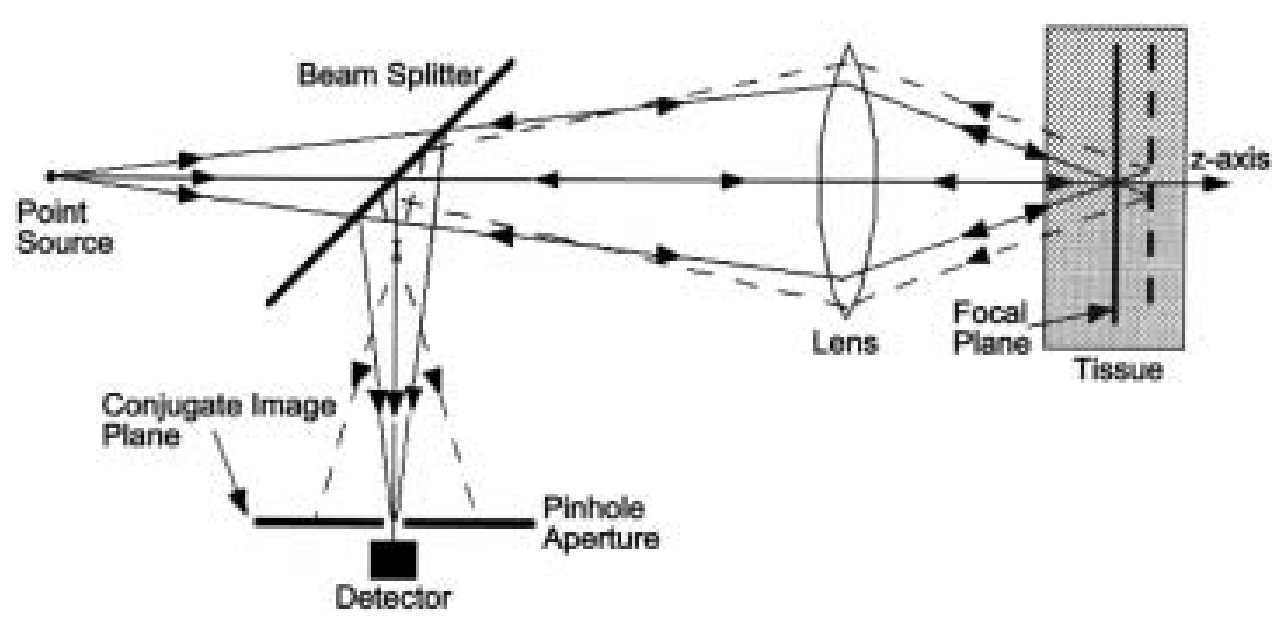

Fig. 1. Diagram of confocal sectioning concept.

points illuminated and ordinarily would degrade image resolution. Light reflected from the focal region (solid line) is refocused by the lens and partially reflected by the beam splitter to a point at the conjugate image plane. If a small aperture is centered on the focused beam in the conjugate image plane, a majority of light returning from the focal region is passed to the detector. Light reflected from depths greater than the focus region (dashed line) is diverging and spread out when it reaches the pinhole, so the pinhole aperture significantly reduces its intensity, thereby increasing resolution. Similar rejection occurs for light coming from depths less than the focal region. Thus, the confocal system isolates light returning from a finite volume, without need for physical sectioning. Scanning the focal spot in the axial and radial dimensions forms an image of reflectance values from the focal region of each point in the sample. In epithelial tissue, resolution of $1 \mu \mathrm{m}$ has been achieved with a 200-400 $\mu \mathrm{m}$ field of view and penetration depth up to $500 \mu \mathrm{m}$ (Table 1) [3].

Epithelial pre-cancers and cancers are associated with a variety of morphologic and architectural alterations, including increased nuclear size, increased nuclear/cytoplasmic ratio, hyperchromasia, and pleomorphism [1]. Figure 2 depicts the transition from normal epithelium to micro-invasive cancer. In the oral cavity, typical epithelial thicknesses range from 200-500 $\mu \mathrm{m}$, and cell diameters range from 10-20 $\mu \mathrm{m}$. Confocal imaging thus is suited ideally both from a resolution and penetration depth perspective to image the neoplastic transformation process in vivo. Figure 3 shows a comparison of confocal and histologic images of normal and neoplastic images of cervical tissue. These images illustrate the hallmark differences between nor- mal epithelium and early neoplastic transformation and show the potential of this technology: histologic quality information can be obtained without the need for biopsy and expensive subsequent sample processing.

\subsubsection{Fiber-based reflectance confocal microscopy}

The application of confocal imaging to detection of pathology in epithelial tissues other than the skin has been limited by the difficulty in accessing these organ sites. A number of groups have attempted to develop flexible endoscopes to record confocal images in vivo based on single mode optical fibers. Approaches to fiber optic confocal imaging can be divided into two categories: (1) those based on a single optical fiber that is scanned to produce images, and (2) those based on bundles of single-mode optical fibers.

In the first approach, a single-mode optical fiber is used to deliver illumination light to the object to be imaged and to collect the resulting backscattered light from the illuminated focal volume. Relay optics are used to image the fiber face onto the object. The face of the fiber acts both as the emitting source and as a point detector so that confocal detection is obtained. When a single optical fiber is used, the illumination light must be scanned in two lateral directions to obtain en face images. Several approaches have been proposed to achieve this scanning, including moving the object to be imaged [6], scanning a delivery and a collection fiber synchronously to achieve directly viewable images [7], coupling the fiber to a reading head of a compact disc player and scanning the reading head [8], using a grating to spectrally map a broadband light source from a fiber onto a line within the object [9], or scanning the fiber and a small objective 
Table 1

Comparison of high resolution optical imaging techniques

\begin{tabular}{llll}
\hline Approach & Resolution (lateral/axial $\mu \mathrm{m})$ & Penetration depth $(\mu \mathrm{m})$ & Limitations of the technology \\
\hline Reflectance Confocal Microscopy: non-fiber & $<1 \mu \mathrm{m} / 3 \mu \mathrm{m}$ & $100-500 \mu \mathrm{m}$ & - Penetration depth \\
Reflectance Confocal Microscopy: fiber-based & $2 \mu \mathrm{m} / 6 \mu \mathrm{m}$ & $100-200 \mu \mathrm{m}$ & - Penetration depth \\
OCT with SLD source & $30 \mu \mathrm{m} / 10 \mu \mathrm{m}$ & $2,000 \mu \mathrm{m}$ & - Lateral resolution \\
OCT with fs laser source & $3 \mu \mathrm{m} / 1 \mu \mathrm{m}$ & \\
OCM & $2 \mu \mathrm{m} / 10 \mu \mathrm{m}$ & $1,000 \mu \mathrm{m}$ & - System complexity \\
Fluorescence & $3 \mu \mathrm{m} / 10-25 \mu \mathrm{m}$ & $60 \mu \mathrm{m}$ & - Weak autofluorescent signal \\
& & & - Penetration depth \\
\hline
\end{tabular}

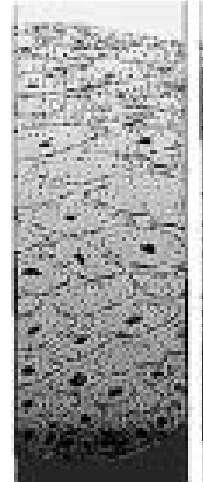

A

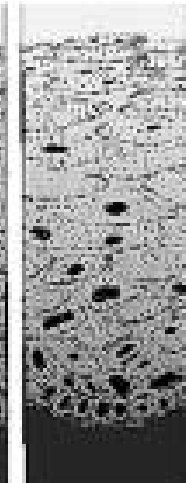

B

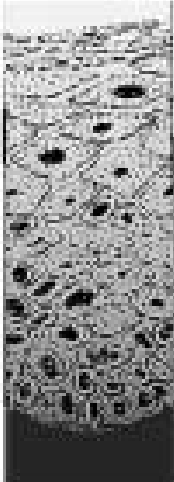

C

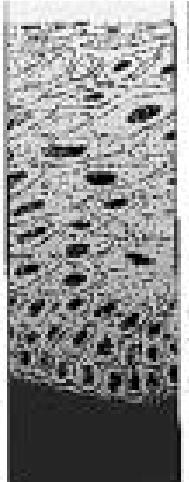

D

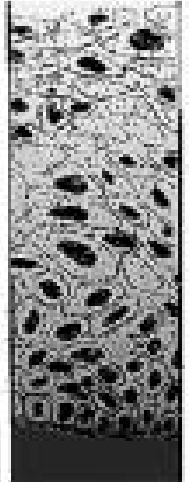

$\mathbf{E}$

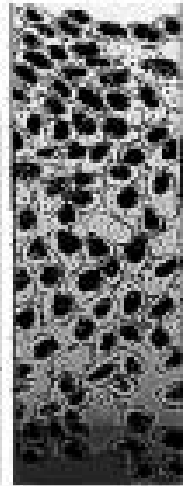

$\mathbf{F}$

Fig. 2. Cross section of squamous epithelium illustrating development of neoplasia. Cells along the basement membrane of normal epithelium (A) are responsible for continual epithelial regeneration. They are less differentiated than superficial epithelial cells and have a larger N/C ratio. As pre-cancer develops (B-D), the fraction of the epithelium occupied by less differentiated cells increases. When the entire epithelium contains neoplastic cells, the lesion is a carcinoma in situ $(\mathrm{E})$. When neoplastic cells break through the basement membrane $(\mathrm{F})$, micro-invasive cancer is present.

lens mounted on a cantilever scanner by electrostatic forces $[10,11]$. The only images of biological samples reported by the above approaches are red blood cells atop glass slides $[10,11]$, which increases the refractive index differences substantially ( $\Delta n \sim 0.20$ ) beyond what is available in vivo $(\Delta n \sim 0.07)$. The image acquisition time for the above approaches also is too slow (at least 0.5 second) to permit real-time imaging. Furthermore, these scanning mechanisms are difficult to miniaturize for endoscopic applications. Recent advances in micro-electromechanical systems (MEMS) have enabled miniaturization of the scanning mechanism and focusing optics, which also facilitates higher scan rates. Figure 4(a) diagrams the light path in the scanning head of one such system [12]. The scanning head consists of two silicon-micromachined mirrors and a grating lens with overall dimensions of $6.5 \mathrm{~mm} \times$ $2.5 \mathrm{~mm} \times 1.2 \mathrm{~mm}$. Figure 5 shows a scanning electron micrograph of the scanning mirror measuring $500 \mu \mathrm{m}$ $\times 600 \mu \mathrm{m}$. An image of a chrome grating was acquired using a raster scan with a $20 \mathrm{~Hz}$ frame rate.

The other technique, first proposed by Gmitro and Aziz [13], uses a fiber optic bundle between the ob- jective lens and the rest of the microscope to eliminate the need for miniaturization of the scanning mechanism. The fiber optic bundle consists of many smallcore diameter fibers. Confocal images can be obtained by scanning the illumination light across the proximal end of the bundle. An additional aperture placed at the conjugate image plane in front of the detector assures that only light from the source/detection fiber is coupled to the detector. Juskaitis et al. [14] developed a reflectance confocal microscope using a fiber optic bundle and a broadband light source. In this system, real-time images are obtained by using tandem scanning, but the sensitivity of this system is limited by the low efficiency of tandem scanning. In another approach, higher light efficiency has been achieved by point scanning with a laser source and two galvanometric scanning mirrors [15] (Fig. 4(b)); reflectance confocal images of epithelial cells and tissue are obtained with a resolution similar to those of non-fiber confocal systems. In this approach, the required speed of a fast line scan for real-time imaging can be attained only by resonant galvanometers, which produce image distortion because of the sinusoidal movement. One alterna- 

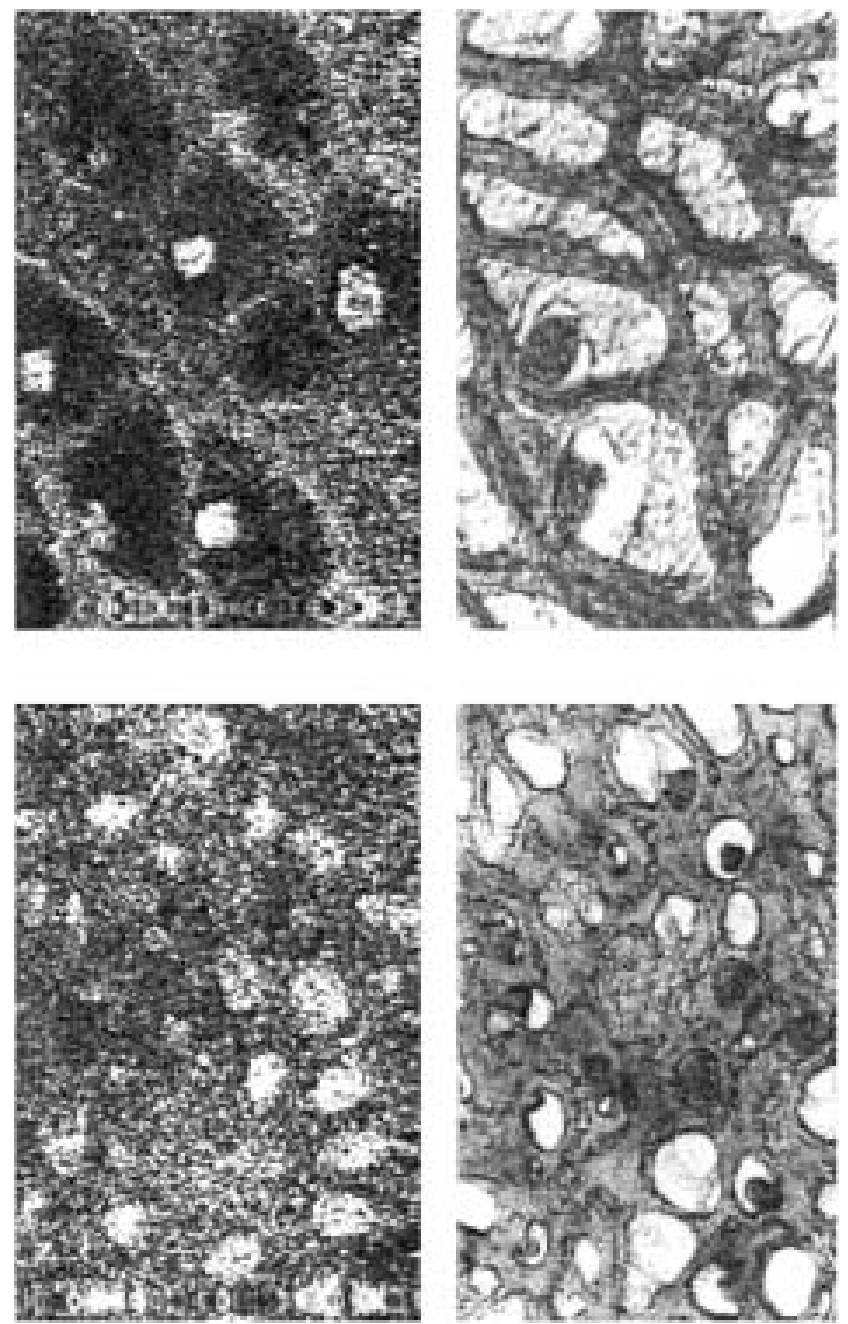

Fig. 3. Top: Images of normal cervical biopsy after (left) application of acetic acid. Image on the right is an H\&E stained frozen section from this biopsy. The two fields are different. Bottom: Images of abnormal cervical biopsy after (left) addition of acetic acid. Image on the right is an H\&E stained frozen section from this biopsy. The two fields are different.

tive approach has been presented to remove the use of fast-line scans by scanning a line illumination pattern across the proximal end of an incoherent fiber bundle, which transforms the line to a random set of spots at the distal end of the bundle [16]. Recently, an approach based on a digital micromirror device (DMD) was reported [17]. A DMD with high contrast, high pixel count, and fast response is used to discretely illuminate fiber cores in a coherent imaging bundle (Fig. 4(d)). The confocality of this system is enhanced by precisely illuminating a single fiber in the bundle and effectively blocking unwanted light from surrounding fibers and cladding material.

Alternatively, fiber optic confocal microscopes can be constructed to measure fluorescent light generated in tissue. The principal components of fiber optic fluorescence confocal microscopes are similar to their reflectance counterparts except for one advantage: the Stokes shift between the excitation light and emitted fluorescence allows for simple rejection of the specular reflection from fiber end faces by filtering. One fluorescence confocal system with real-time endoscopic imaging capability has been constructed by scanning a line illumination across a coherent fiber bundle and using a slit aperture to reject out-of-focus light (Fig. 4(c)) [18].

\subsection{Optical coherence tomography}

OCT is another optical modality with the potential to image tissue with sub-cellular resolution 


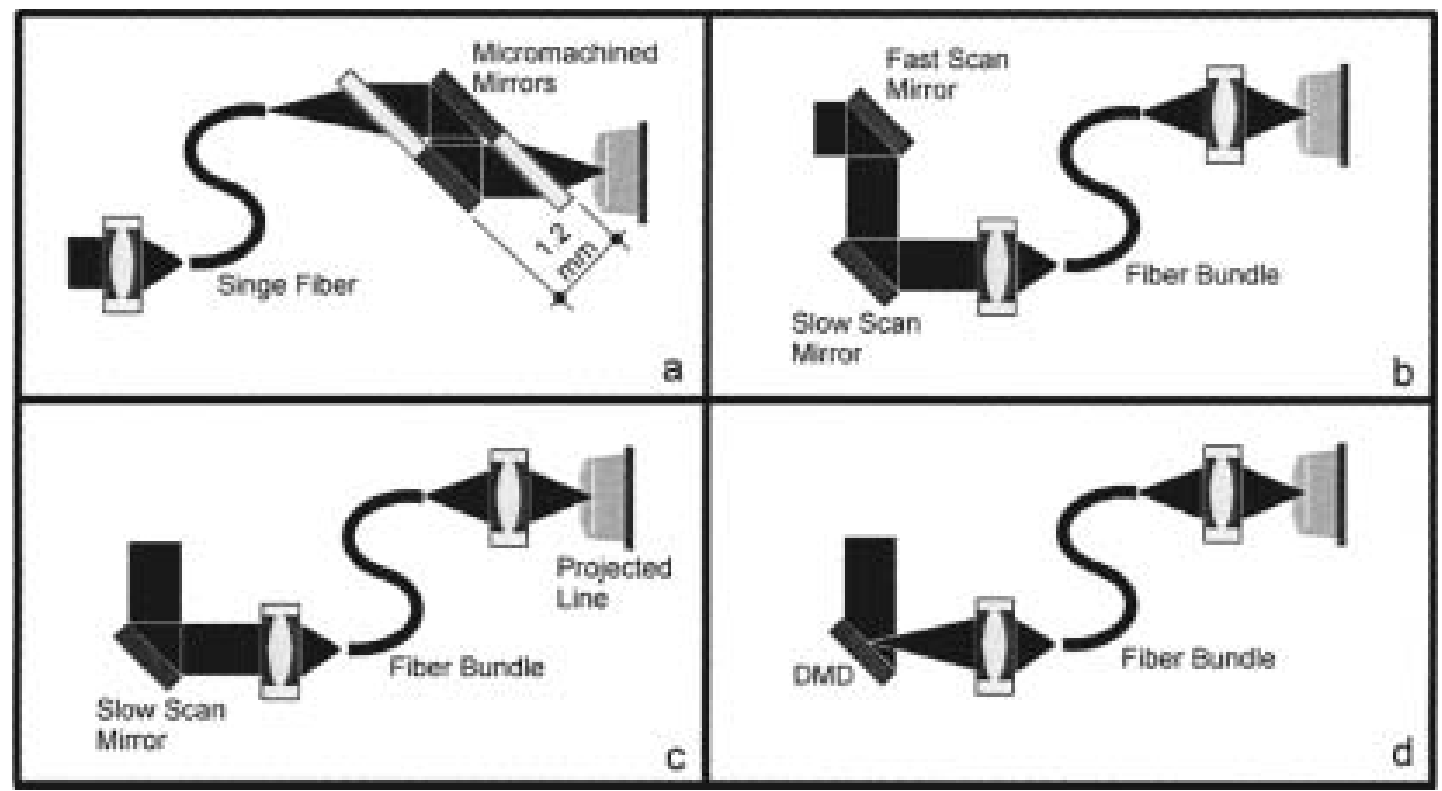

Fig. 4. Various scanning methods for fiber-optic based confocal microscopes. All elements to the right of the fibers in the diagrams are miniaturized. a. Scanning is performed on a silicon chip placed within the endoscopic channel. b. X-Y scanning is performed entirely at the proximal end of a fiber bundle. c. A line is scanned across a fiber bundle with a slow scan mirror; only one-dimensional scanning is performed. d. A fast-switching DMD mirror is used to illuminate individual fibers within the fiber bundle.

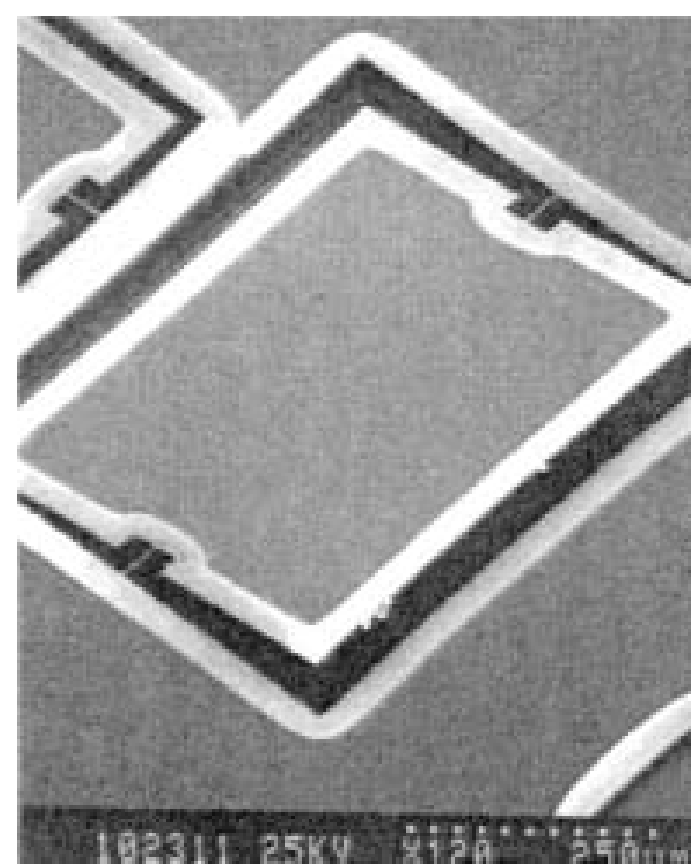

Fig. 5. Scanning electron micrograph of the scanning mirrors produced using MEMS technology [12].

(Fig. 6) [19]. In OCT, a two-dimensional reflectance map of backscattered light is acquired in a manner analogous to B-mode ultrasound imaging. In ultrasound imaging, signal reflected from the depth of interest is selected based on the time delay between the incident and reflected signal. Because the speed of light is so great, it is difficult to measure time-of-flight information for light; instead, interferometric techniques are used to select the light reflected from the depth of interest. Figure 7 shows a block diagram of a basic OCT system [2]. Light from a near-infrared laser is split into a reference and sample arm by a Michelson interferometer (the 50/50 coupler in Fig. 7), which then recombines reflected light from the two arms into one signal. An interferometric signal is detected only when the reflections are nearly matched in optical pathlength [20]. The use of a broadband source with a correspondingly short coherence length causes the interferometric signal to fall off rapidly as the difference between the two-arm delays increases, providing strong rejection of out-of-focus light. If a low numerical aperture (NA) objective is used to focus light inside the tissue, the axial resolution of the system is independent of the focusing optics and strictly a function of the sourcecoherence length. When low NA optics are combined with a 1300-nm broadband source and heterodyne detection allowed by modulation of the reference arm's pathlength, OCT images can be obtained at depths of up to $2 \mathrm{~mm}$ [21]. In imaging of epithelial tissue, OCT typically provides approximately $3-35 \mu \mathrm{m}$ lateral and 


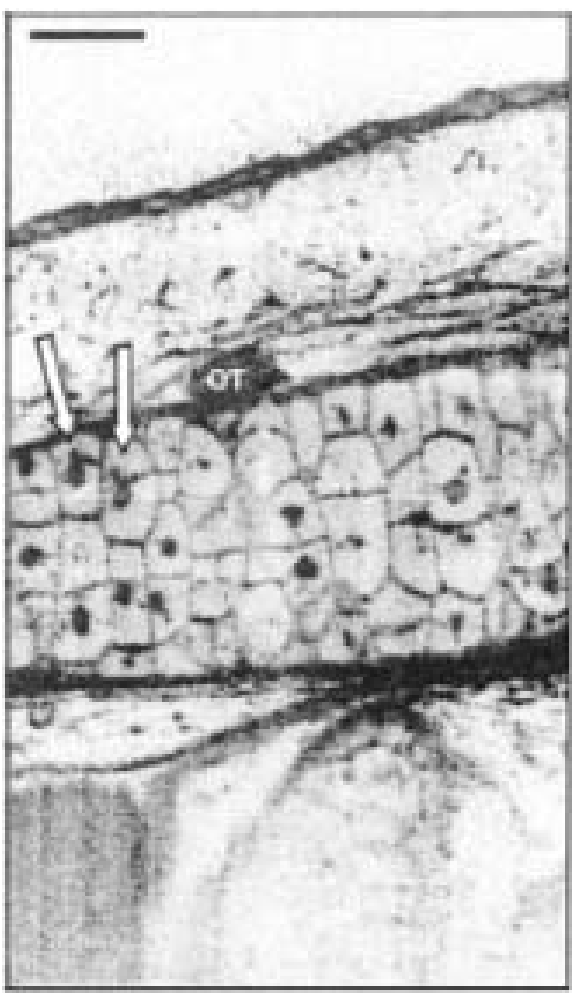

Fig. 6. In vivo sub-cellular level resolution $(1 \mu \mathrm{m} \times 3 \mu \mathrm{m}$, longitudinal $\times$ transverse) tomogram of an African frog tadpole (Xenopus laevis). Multiple mesanchymal cells of various sizes and nuclear-to-cytoplasmic ratios, olfactory tract (OT) and intracellular morphology, as well as mitosis of two cell pairs (arrows), are clearly shown. Bar: $100 \mu \mathrm{m}[19]$.

15-30 $\mu \mathrm{m}$ axial resolution, depending on the amount of focusing performed in the sample arm and the source used in the system (Table 1) [20]. This resolution is not always enough to see sub-cellular details. Several approaches to overcome this limitation are reviewed briefly in Section 3 of this article.

Scanning the reference arm of the interferometer yields the backscattered signal as a function of depth below the surface at one point on the tissue. Twodimensional OCT images perpendicular to the tissue surface can be constructed by obtaining multiple depth profiles, moving the optical beam laterally across the tissue surface between scans [2] to build two-dimensional images. In this case, an endoscope only has to scan one axis, instead of the two required for en face imaging as in RCM. Thus, OCT images have been obtained using fiber optic endoscopes from a number of internal organ sites. Both lateral- [22,23] and rotary-scanning $[24,25]$ catheter-based probes have been used to image the gastrointestinal tract [26-28], esophagus [29,30], proximal stomach [23], and atri- oventricular node [31]. A miniaturized, electromechanically lateral scanning OCT probe also has been combined with a gastroscope [32] and laparascope [33] to image mucous membranes of the esophagus, larynx, stomach, urinary bladder, uterine cervix, skin, and oral cavity [34]. Other probes have collected OCT images from the uterine cervix [35], teeth [36], and intravasular implants [37].

\subsection{Optical coherence microscopy}

A technique that combines the advantages of RCM and OCT is optical coherence microscopy (OCM). OCM can yield the sub-cellular resolution typical of confocal microscopy, while maintaining the sensitivity and deep penetration depth of OCT. Figure 8 shows a block diagram of an OCM system [38]; an optical coherence microscope is very similar to an OCT system, except that the sample arm comprises a confocal microscope with high NA optics and image scanning is performed en face (or parallel to the tissue surface). Many groups have built instruments with components of an OCM system. Bashkansky [39,40], Beaurepaire [41], Podoleanu [42-45], and $\mathrm{Xu}$ [46] all have demonstrated OCT systems capable of producing en face images, but their systems use low NA optics in the sample arm. Beaurepaire has reported an en face imaging, high NA system, but did not use modulation to allow heterodyne detection [47]. Schmitt introduced a system with dynamic depth focusing and high NA optics, but the instrument was capable only of producing longitudinal scans [48]. Izatt's group was the first to describe an OCM encompassing all of the traits listed above [38,49] (Fig. 8), with an improved, faster system discussed in [50]. His work was followed by Hoeling, who developed another fully capable OCM used to image embryos [51] and plant cells [52]. While all of these systems are tabletop versions without endoscopic capability, this technique has the promise to resolve both confocal penetration depth and OCT resolution issues currently limiting the techniques' ability to detect cancer. Current OCM systems provide lateral and axial resolution of $2 \mu \mathrm{m}$ and $10 \mu \mathrm{m}$ [49] that compares favorably with RCM and is a significant improvement over a typical OCT system (Table 1).

\section{Current and potential applications of the technology in early cancer detection}

RCM and OCT provide the ability to image tissue morphology and architecture non-invasively. A num- 


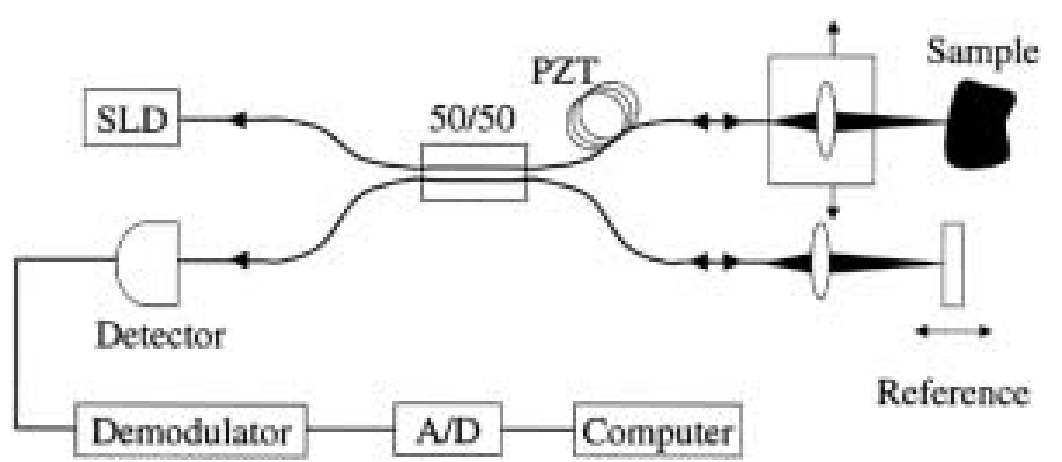

Fig. 7. Schematic of an OCT system [2].

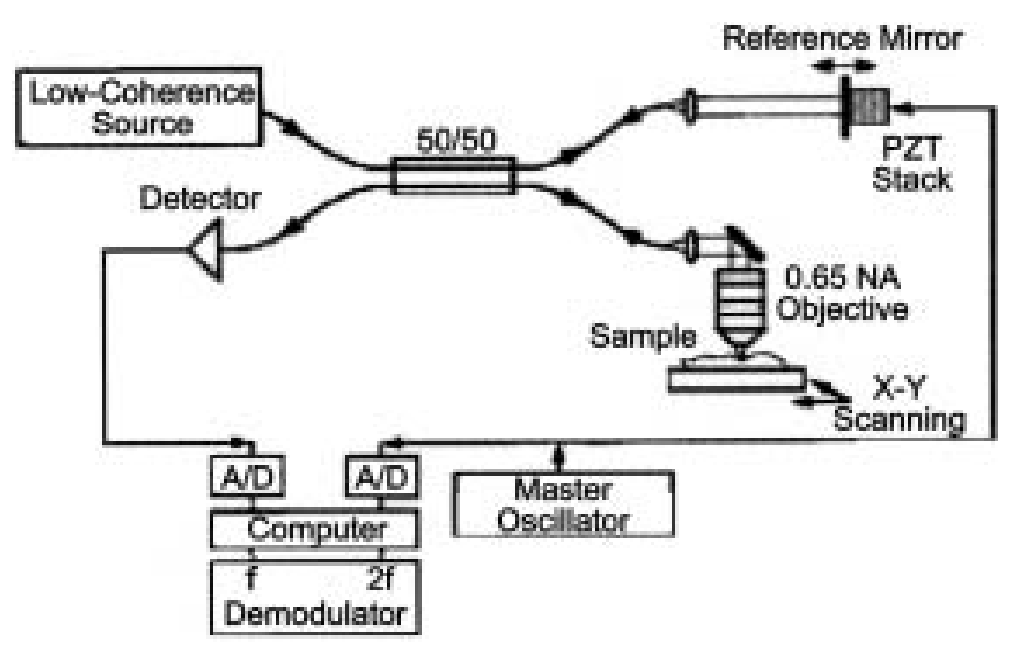

Fig. 8. Schematic of an OCM system [38].

ber of pre-clinical and clinical trials have been carried out to assess their ability to image the characteristic features of pre-neoplastic and neoplastic lesions. The results of these trials and the current limitations of these technologies are reviewed in the next section.

\subsection{Confocal microscopy}

To date, RCM has been used to image cellular and sub-cellular features of pre-cancerous and cancerous lesions in the human skin $[3,53]$, oral cavity [54], cervix [55], and esophagus [56] (Fig. 9). In skin [3,53,57-59], confocal imaging can provide detailed images of cell morphology and tissue architecture throughout the entire epithelium, as well as image sub-epithelial blood flow in capillaries. In skin, cytoplasmic melanin granules provide strong contrast because they increase backscattering by virtue of melanin's high index of refraction $(n=1.7)$ compared to cytoplasm ( $n=1.37$ ) [3]. Thus, confocal images of skin show bright cells with dark nuclei $[3,60]$. Quantitative analysis of cellular and morphologic features (e.g.. nuclear diameter and nuclear to cytoplasm [N/C] ratio) shows good agreement with histology [53], suggesting that confocal microscopy can identify pathology noninvasively in vivo. A number of pathologic skin conditions have been investigated using confocal microscopy including allergic contact dermatitis [60], actinic keratoses [61], onychomycosis [62], psoriasis [63], DarierWhite's disease [64], sebaceous hyperplasia [65,66], cherry angioma [67], and folliculitis [68]. Recently, confocal imaging has been used to image neoplastic skin lesions $[69,70]$. Confocal images identified intraepidermal melanoma and benign skin based on a loss of the honeycomb pattern of keratinocytes and architectural disarray [69]. In a second study [70], benign melanocytic lesions showed nests of uniformly circular cells, while confocal images of melanomas showed atypical cells in architectural disarray [70]. 

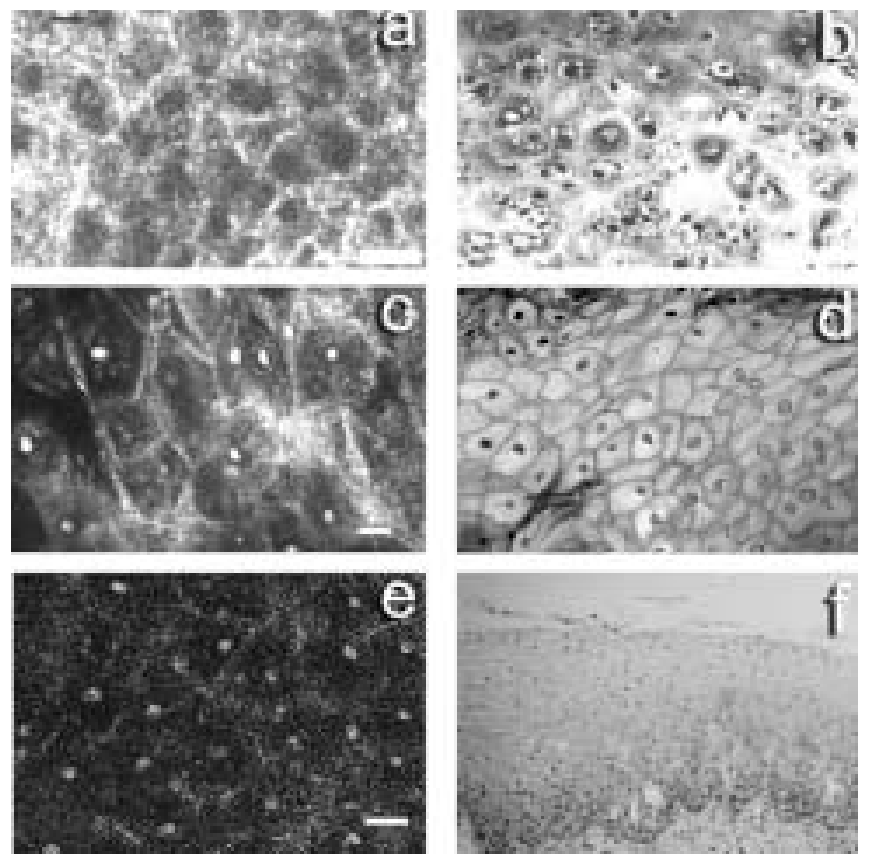

Fig. 9. Non-fiber-based confocal images of human skin (a), the oral cavity (b) and the cervix (c). Nuclei and cell outlines can be visualized in all three tissue types. The nuclei are relatively darker in the human skin compared to the cytoplasm. The opposite is observed in the superficial images of the oral cavity and cervix in which the nuclei are brighter. Images correspond well to histology (d, e, f). All images shown are en face with the exception of $\mathrm{f}$, which is in the standard orientation for histology. The scale bar is 50 microns.

Confocal images also have been obtained from amelanotic epithelial tissues such as the GI tract [56], cervix [57], and lip and tongue [71,54]. In contrast to skin, confocal images of amelanotic epithelium show backscattering from cell nuclei and from borders between cells [56,71]. In a study of the esophagus [56], nuclear to cytoplasmic ratios were extracted from confocal images of normal esophagus and esophageal cancer; differences were statistically significant and could be used to identify cancer with a diagnostic accuracy of $90 \%$ [56].

In cervical tissue, acetic acid has been used as a non-specific contrast agent to aid in visualizing nuclei. Acetic acid increases nuclear backscattering throughout the epithelium, resulting in confocal images that show bright nuclei and dark cytoplasm. In a pilot study, we obtained confocal images from 25 paired colposcopically normal and abnormal biopsies. Figure 10 shows typical confocal images of normal and pre-cancerous cervical tissue. Confocal images of precancerous cervical tissue show increased numbers of nuclei per unit area and increased nuclear to cytoplasmic ratios. Features of the confocal images agree well with corresponding morphometric features of histologic images from the same biopsies [72]. Quantitative measurements of the nuclear to cytoplasmic ratio can be extracted from the confocal images and can identify high-grade dysplasia with a sensitivity of $100 \%$ and a specificity of $91 \%$ relative to histopathologic diagnosis.

Fiber optic confocal microscopes have been developed with lateral and axial resolution similar to the nonfiber optic systems described above. As an example, we developed a fiber optic confocal reflectance microscope and have used this system to image cervical tissue with sufficient resolution and acquisition speed for use in the clinical setting [15]. The first prototype of the microscope had a standard 40X microscope objective and was approximately $2.5 \mathrm{~cm}$ in diameter. Images of colposcopically normal and abnormal cervical biopsies are shown in Figs 11(a) and (b), respectively [15]. The images show similar detail as obtained with the nonfiber confocal system (Fig. 10). This system recently was modified to include a miniature objective lens for use in the cervix and oral cavity (Fig. 12) [15]. Confocal images of human lip (Fig. 13) and cervix have been acquired in vivo with acetic acid solution as a contrast agent. The modified system currently is being used in an in vivo pilot study on the cervix.

The confocal microscopes described thus far have imaged light reflected from tissue. Alternatively, confocal microscopes can image fluorescence light generated within a tissue $[13,17,18,73-75]$. The Stokes shift 


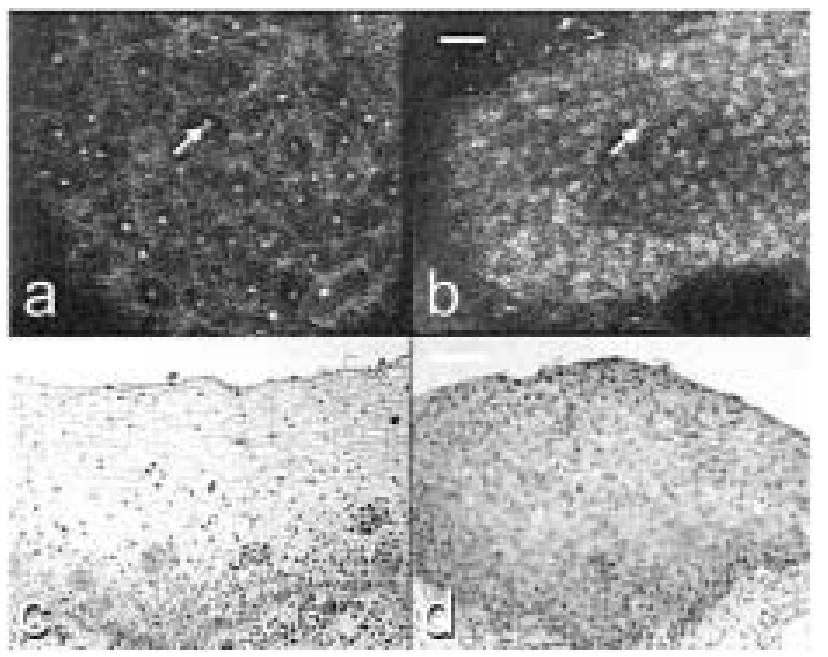

Fig. 10. Confocal images of ex vivo cervical tissue using a non-fiber based system. Nuclei can be visualized easily (arrow). Difference in nuclear density and area are apparent between the normal (a) and high-grade dysplastic tissue (b). Changes in morphology also are apparent in the corresponding histologic sections (c, d). The scale bar is $50 \mu \mathrm{m}$ for the confocal and $100 \mu \mathrm{m}$ for histology [72].

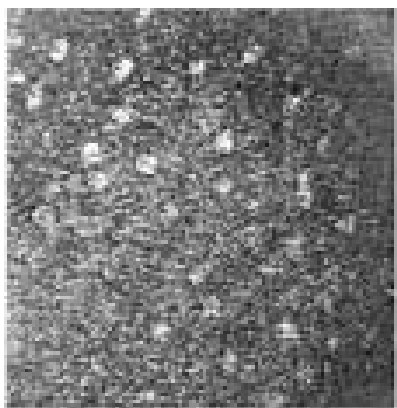

(a)

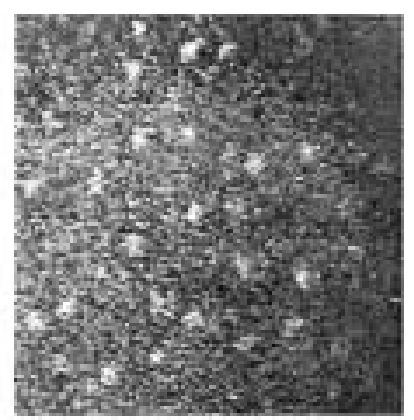

(b)

Fig. 11. Confocal images of cervical biopsies obtained with a fiber optic confocal microscope; (a) colposcopically normal tissue at a depth of $80 \mu \mathrm{m}$; (b) colposcopically abnormal tissue located $60 \mu \mathrm{m}$ below tissue surface [15].

between the excitation light and emitted fluorescence allows for simple rejection of the specular reflection produced at the faces of the fiber bundle. Gmitro reported a design based on a coherent fiber bundle [13], while Delaney reported an approach based on a single optical fiber [74]. Fluorescence images of biological samples show high spatial resolution (lateral resolution $\sim 3 \mu \mathrm{m}$, axial resolution $\sim 15 \mu \mathrm{m}$ ) (Table 1 ), and include a Feulgen-stained onion root tip [74], cultured PC3 cells [18], and human prostate [18] and rat colon [75] cells stained with vital fluorescent dyes. Recently, autofluorescence of lung tissue has been reported using a confocal fiber bundle addressed with a DMD [17].

\subsection{Optical coherence tomography}

Current OCT systems that have been tested clinically do not provide images with the sub-cellular resolu- tion characteristic of reflectance confocal microscopy. However, endoscopic OCT images illustrate architectural differences associated with the epithelial and stromal layers as pre-cancers and cancers develop. In normal tissue, a clear distinction between the backscattering of the epithelium and stroma is evident in OCT images, and this distinction is reduced in OCT images of pre-cancerous and cancerous tissues of the larynx, uterine cervix, colon, urinary bladder [23,27,32,76] and esophagus (Fig. 14) [29,30].

\section{Limitations of the technology}

Potential clinical applications of RCM and OCT are limited by fundamental principles of light interactions with turbid human tissue and by the current level of 

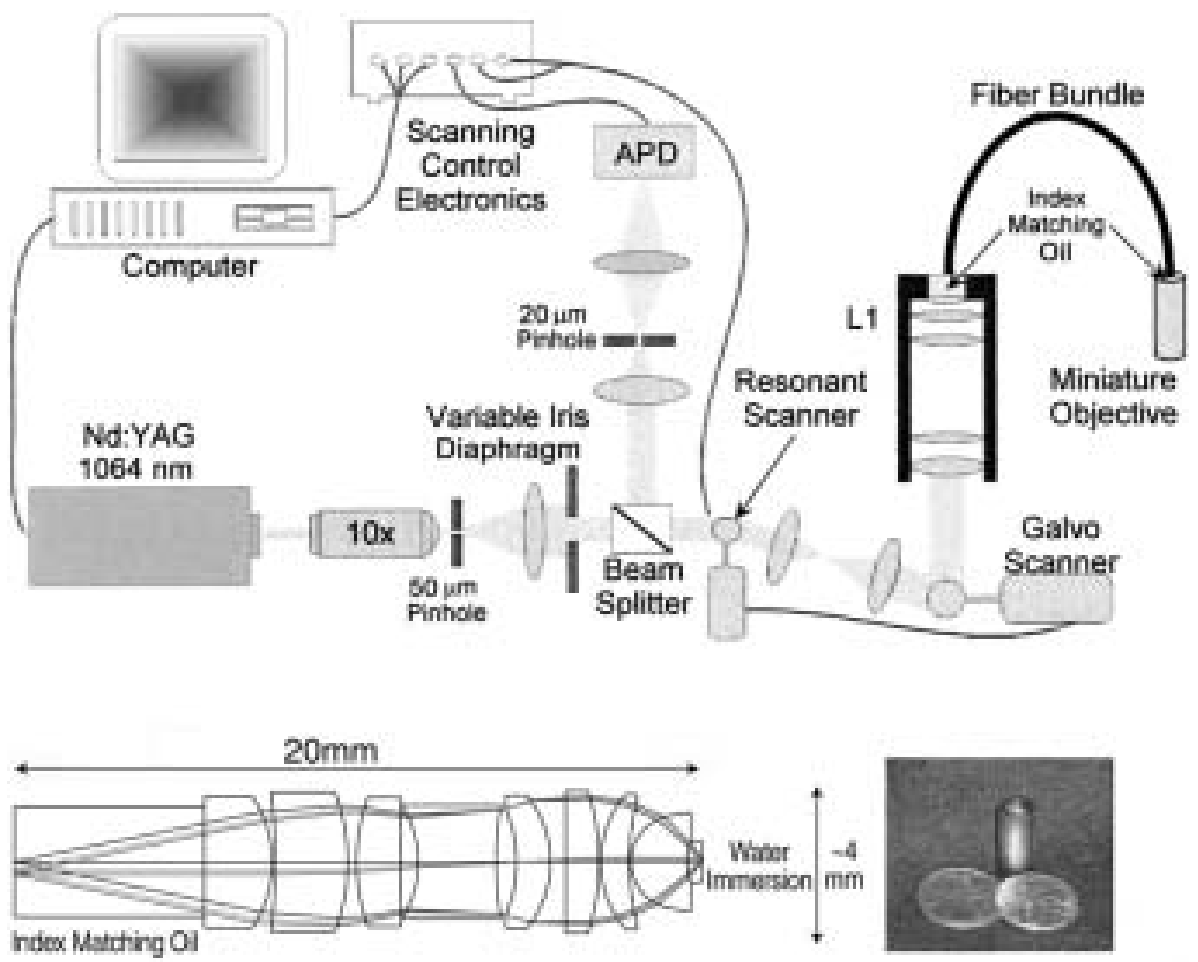

Fig. 12. Top: System diagram of a confocal endoscope utilizing a fiber optic bundle; en face images of the object are obtained by scanning the illumination spot across the proximal bundle end. A pinhole aperture is placed in front of the avalanche photodiode (APD) to reject light from out-of-focus regions within the object [15]. Bottom: Miniature microscope objective. The left image shows the optical design, and the right image is a photo of the miniature objective. The outer diameter of the objective is $7 \mathrm{~mm}$, and the length is $22 \mathrm{~mm}$.

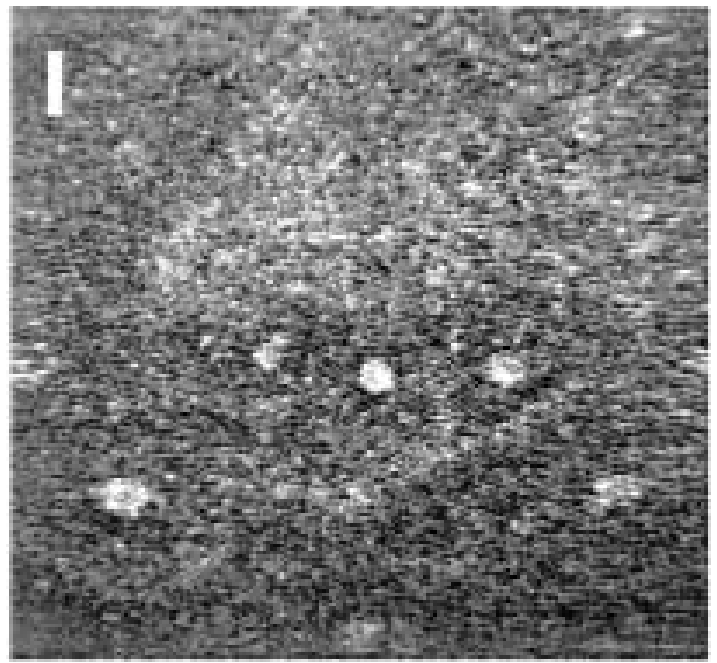

Fig. 13. In vivo image of human lip obtained with a fiber optic confocal endoscope. Acetic acid was used as the contrast agent. The scale bar is $20 \mu \mathrm{m}$ [15].

technology development. Here, we briefly discuss both of these limitations, their implications in the case of high-resolution imaging of epithelial tissue, and re- search activities focused on overcoming the limits of RCM and OCT.

\subsection{Confocal reflectance microscopy}

Confocal reflectance images with sub-cellular resolution can be obtained up to $500 \mu \mathrm{m}$ deep within the human tissue; this is sufficient to image throughout the entire epithelial thickness in most of the tissues. For example, high-resolution confocal reflectance images have been reported from depths of up to $350 \mu \mathrm{m}$ in human skin [3] and $450 \mu \mathrm{m}$ in the oral mucosa [54]. However, the penetration depth of RCM is limited by two major factors: signal-to-noise ratio and background due to out-of-focus scattering. These factors have been examined extensively [48,77-81]. Izatt used single backscatter theory to estimate that penetration depth is limited by the signal-to-background (S/B) ratio to 5-8 optical depths (OD), where optical depth is equal to the total attenuation coefficient, $\mu_{t}$, times the depth in the tissue [48]. When multiple scattering due to deep penetration into tissue was taken into account, Schmitt found that this limit is limited by the signal- 

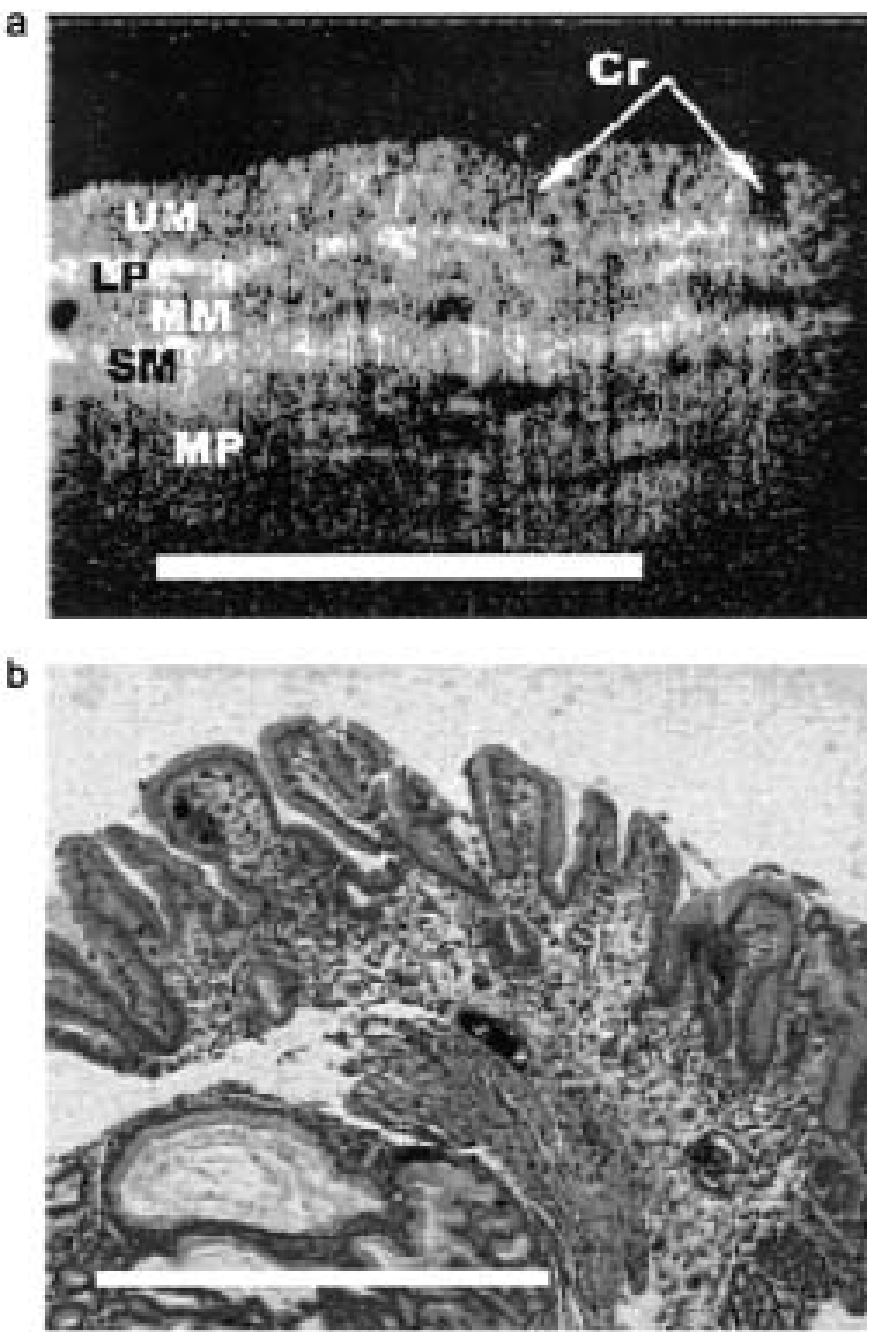

Fig. 14. OCT image vs. histology of Barrett's esophagus. a. OCT image. b. The corresponding histology. The low-scattering layer represents crypts in the superficial layer $(\mathrm{Cr})$. UM, upper mucosal layer; LP, lamina propria; MM, muscularis mucosa; SM, submucosa; MP, muscularis propria. Scale bars represent $1 \mathrm{~mm}[29]$.

to-noise ratio (SNR) and falls to 3-4 ODs [78]. While Schmitt's studies were performed using large normalized pinholes of 8 to 17 optical units (o.u.), his results were confirmed by Smithpeter, who used experimental results to show that when a confocal system approaches ideal confocal resolution (normalized pinhole size $\leqslant 3$ o.u.), penetration depth is limited to $3-4$ ODs for a 0.05 index mismatch [81].

The miniaturization of confocal microscopes needed for endoscopic applications imposes additional challenges that limit current clinical applications of RCM. The main limitation in development of fiber-based confocal systems is strong specular reflection, which is generated at the proximal and distal surfaces of optical fibers. This reflection can exceed the intensity of light backscattered from the tissue by several orders of magnitude. A number of solutions have been proposed to address this problem, including index matching with immersion oil [15], angle-polishing the fiber faces $[11,12]$, and anti-reflection coating of the fiber faces.

There also are specific problems associated with the development of confocal endoscopic microscopes based on single-fiber probe and fiber bundle approaches. The major problem in designing single-fiber endoscopes is the complexity of miniaturizing the scanning mechanism and objective lens at the distal end. Recently, one system based on the MEMS approach was reported with resolution, dimensions, and acquisition speed required for in vivo imaging; however, the 
sensitivity of the system was not enough to detect reflected light from refractive index mismatches characteristic of soft tissues such as epithelium [12]. The insufficient throughput can be attributed to low efficiency of the objective lens and mirrors and coupling loss of the fiber.

For the fiber bundle approach, the lateral resolution of the system is limited by the sampling pitch in the bundle, which is determined by the distance between neighboring fibers and magnification of the objective lens. Increasing the magnification of the objective lens can enhance the lateral resolution but also increases the complexity of designing the objective lens. The spatial resolution also can be enhanced by using fiber bundles with smaller fiber separations; however, coupling loss at the fibers increases if the fiber diameter is smaller than the illumination spot. Moreover, when the size of the fibers decreases, the illumination light might be coupled into multiple fibers, which lessens the optical sectioning ability of the confocal microscope.

\subsection{Optical coherence tomography and optical coherence microscopy}

While the increased penetration depth of OCT is useful clinically, the most significant drawback to OCT is that, while its resolution is sufficient for macroscopic imaging of tissue, it is not able to resolve sub-cellular detail. Efforts to increase the resolution of OCT currently are focused in two general areas: (1) improving axial resolution without affecting the long depth of focus needed for deep penetration depths, and (2) increasing both the lateral and axial resolution through higher NA optics. Attempts to improve axial resolution have concentrated primarily on decreasing the source coherence length. A system using a Kerr-lens mode-locked femtosecond Ti:sapphire laser provided $\sim 1 \mu \mathrm{m}$ axial resolution in tissue (Table 1) [19], but its expense is prohibitive for clinical applications. Other authors have synthesized broadband sources with short coherence lengths by combining two or three superluminescent diodes [48,82-84], resulting in resolutions from $4-8 \mu \mathrm{m}$ in tissue. Other non-typical sources proposed for use with OCT systems have included continuum generation in an air-silica microstructure fiber ( $\sim 2 \mu \mathrm{m}$ in tissue) [85] and a tungsten halogen lamp with a coherence length in the $1 \mu \mathrm{m}$ range [86]. In addition to improving the sources used for OCT, resolution has been improved through deconvolution techniques $[87,88]$. Another area of research that shows great promise in improving the resolution of OCT is through increasing the focusing power of the sample arm objective. Since increasing the numerical aperture of the objective also decreases its depth of focus, many systems have incorporated dynamic focus mechanisms either by adjusting pathlength within the reference arm while scanning [48,89], dynamically shifting the focus through the sample [90], or using zone-focusing and image fusion techniques [19].

Research into OCM is still in its early stages, but the technique promises to overcome many of the limitations of confocal microscopy and OCT, such as penetration depth or resolution. The primary problems associated with OCM are the overall system complexity needed to incorporate all components, especially complicating its use in endoscopic applications. Since en face imaging is used, an endoscope must perform the two-dimensional scanning that has slowed confocal endoscopic development. In addition, path lengths between the reference and sample arms must remain matched (to within the source coherence length) as the systems scan more deeply into tissue.

An important problem facing all methods of optical imaging of epithelium is the limited sources of native contrast in the tissue. For example, refractive index differences in human epithelium are only 0.05. Detection of these weak sources of signal is challenging. On the other hand, neoplastic progression is characterized by changes in tissue morphology and by molecularspecific alterations. For cancer screening, detection, and prognosis, it is imperative to develop approaches sensitive to these cancer-specific markers. In the next section, we briefly summarize the major hallmarks of cancer progression and discuss how these features can be visualized and enhanced in optical imaging. First, we describe native sources of contrast in tissues containing epithelium that are sensitive to carcinogenesis. Then, we discuss research activities focused on development of exogenous contrast agents that increase the intrinsic contrast or provide new sources of contrast in human tissue. The contrast agents can be divided broadly into two categories: those that enhance the morphological features important for cancer detection and characterization, and molecular-specific contrast agents that enable high-contrast vital imaging of cancer-related molecular alterations.

\section{Current research in disease markers}

Cancer progression is associated with specific changes in the cellular phenotype. These changes, or 
cancer-related biomarkers, can be divided into several categories, including cyto- and histologic markers, and markers that indicate altered proliferation, regulation, differentiation, and genomic instability. Cytologic and histopathologic markers include nuclear features, nucleolar features, and tissue architecture [91,92]. Nuclear features of interest include grade, shape, area, optical density, texture, nuclear pleomorphism, and ploidy. Tissue architectural measurements exploit the finding that disordered nuclei are crowded and irregular. Proliferation, regulation, and differentiation biomarkers are manifested in changes of expression profiles of a number of biomolecules, such as epidermal growth factor receptor (EGFR), proliferating cell nuclear antigen (PCNA), and cytokeratins. It has been recognized that the quantitative detection of biomarkers is a very essential element in grading and the prediction of the evolution of a particular lesion $[93,94]$. It also has been suggested that the biomarkers can provide essential endpoints in direction and monitoring of clinical chemoprevention trials [93].

In the first part of this section, we describe how native sources of contrast inherent for reflectance and fluorescence imaging in epithelial tissue can be used to provide information on cytologic and histopathologic cancer-related biomarkes in vivo. Then, we present exogenous contrast agents that allow us to enhance the native sources of contrast. We also describe approaches to developing molecular-specific contrast agents for vital imaging of biomolecular signatures of cancer.

\subsection{Native sources of contrast}

In reflectance-based optical imaging techniques, the signals obtained are modulated by the scattering properties of tissue being imaged. Light-scattering properties in the epithelium are determined by cellular morphology and refractive index variations in the cells. Confocal microscopy and OCT are sensitive especially to factors that affect high-angle scattering, since these imaging techniques basically provide a map of backscattered light.

The most significant differences between dysplastic epithelial cells relative to normal cells include increased nuclear size, asymmetric nuclear shape, and increased DNA content. Dysplastic nuclei also are hyperchromatic - and the chromatin is irregularly distributed - with areas of coarse clumping and condensation, whereas other areas show chromatin clearing [9597]. Dysplastic changes alter the refractive index profile and the scattering properties of nuclei and, thus, provide a natural contrast mechanism for differentiating between normal and dysplastic tissue. Imaging techniques with sub-cellular resolution, such as confocal microscopy and, potentially, OCT, offer the capability of probing the changes in the scattering properties that occur with dysplasia.

To facilitate interpretation of images obtained using scattering-based optical diagnostic techniques, a quantitative understanding of the relationship between dysplastic changes in the nuclei and light scattering is needed. The Finite-Difference Time-Domain (FDTD) method $[98,99]$ can be used to solve numerically for the scattered electromagnetic field of arbitrarily inhomogeneous structures and, thus, provides a simulation scheme to analyze how the light-scattering properties are influenced by nuclear morphology, DNA content, and chromatin texture. This method recently has been used to investigate changes in the nuclear-scattering properties that occur with progression of cervical intraepithelial neoplasia (CIN) [100,101]. These studies use quantitative histopathologic images of FeulgenThionin stained cervical cell nuclei for incorporation into FDTD modeling. The Feulgen-Thionin stain is stoichiometric for DNA [102]; therefore, the images highlight changes in nuclear morphology, DNA content, and chromatin distribution. Results of FDTD simulations show that the changes associated with dysplasia lead to variations in angular distribution of scattered light and to enhanced scattering intensity in both the forward and backward direction. Figure 15 shows representative images of nuclei from tissue with different stages of CIN. The figure also shows nuclear scattering cross-sections computed through FDTD simulations performed at a wavelength of $900 \mathrm{~nm}$ [100]. The nuclear images in the figure illustrate progressive changes associated with $\mathrm{CIN}$, and the corresponding increase in the scattering cross-sections indicate elevated scattering. Elevation in scattering from dysplastic cervical cell nuclei also has been observed in confocal images of cervical tissue [55,72]. In these images, dysplastic nuclei appear brighter compared to normal nuclei, consistent with the FDTD modeling results.

In the case of fluorescence-imaging approaches, natural contrast can be determined by naturally occurring biological fluorophores: aromatic amino acids (tryptophan, tyrosine, and phenylalanine), reduced nicotinamide adenine dinucleotide (NADH), flavins, porphyrins, collagen, and elastin [103]. Fluorescence spectra measured from normal and dysplastic tissue show differences in autofluorescence patterns, but the biological basis of these differences still is under inves- 


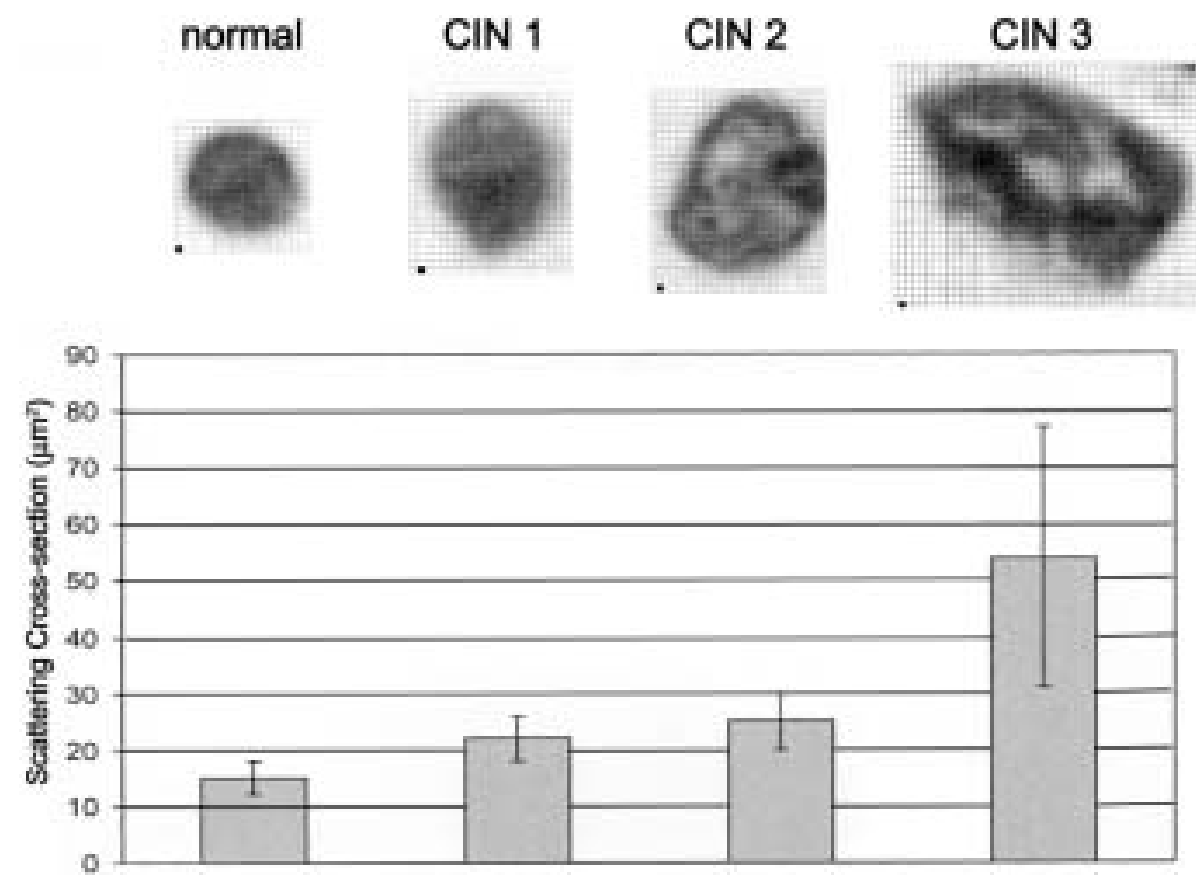

Fig. 15. Above: Images of Feulgen-Thionin-stained cervical cell nuclei in different stages of CIN. Each pixel shown is $0.34 \mu \mathrm{m} \times 0.34 \mu \mathrm{m}$. Below: Scattering cross-sections computed through FDTD simulations. Each scattering cross-section value corresponds to a calculated average over five different simulations.

tigation. A recent study [104] analyzing the autofluorescence images of fresh tissue sections of normal and dysplastic cervical tissue at excitation wavelengths of $380 \mathrm{~nm}$ and $460 \mathrm{~nm}$ demonstrated that, as dysplasia develops, fluorescence from the epithelium increases for $380 \mathrm{~nm}$ excitation, and fluorescence from the stroma significantly decreases for both $380 \mathrm{~nm}$ and $460 \mathrm{~nm}$ excitation. Assuming that NADH is the dominant epithelial fluorophore at $380 \mathrm{~nm}$ excitation, the increase in epithelial fluorescence from the epithelium can be attributed to increased cellular metabolism in dysplastic tissue. The main source of stromal fluorescence is collagen crosslinks [105]. It has been speculated that decrease in stromal fluorescence with progression of dysplasia is due to the breakdown of the collagen crosslinks [104]. Obviously, autofluorescence patterns of tissues can reveal important information about the biochemical progression of dysplasia, but a better understanding of how each different fluorophore affects the observed spectra needs to be established.

\subsection{Contrast agents}

Various exogenous contrast agents have been used to enhance the native contrast observed in tissue. Studies have employed these contrast agents to gain a greater understanding of physiological and molecular processes occurring within tissue, as well as to create more sensitive methods for detecting various biological abnormalities, such as pre-cancerous and cancerous lesions. Here, we concentrate on those agents that currently have the greatest potential for in vivo use in a clinical setting.

\subsubsection{Reflectance-based contrast agents}

Non-specific reflectance-based contrast agents include compounds that increase the native backscattering of the sample. Weak acetic acid has been studied as a contrast agent to increase the backscattered signal from nuclei in ex vivo human breast cancer cells [106] and cervical tissues [55,107]. It is a common clinical contrast agent used to detect areas of cervical dysplasia in vivo due to the whitening effect it has on abnormal tissue areas [107]. Microbubbles have been used as a source of contrast in optical coherence tomography to distinguish the boundary between blood and vessel walls [108]. Gas-filled microbubbles are nonspecific compounds that travel through the circulatory system and provide strong optical contrast within the blood.

Absorption dyes (e.g., toluidine blue) that can significantly alter the scattering profile of epithelial tissue also are used to detect areas of dysplasia. Stud- 


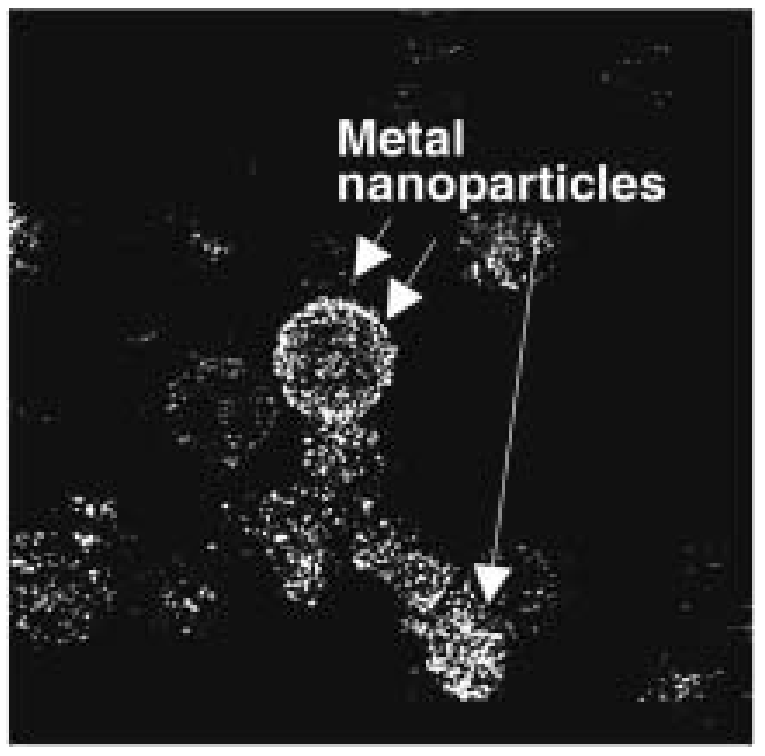

Fig. 16. Cervical cancerous SiHa cells labeled with anti-EGFR $\mathrm{mAb}$ gold particle conjugates.

ies of cervical and oral cavity tissue have shown that toluidine blue concentrates in areas of dysplasia due to the increased cellular membrane permeability [109]. In a study of oral cavity dysplasia, areas of carcinoma and carcinoma in situ retained a dark blue stain following an oral rinse with a $1 \%$ toluidine blue solution, thereby identifying the areas with the greatest pathological change [110]. The dye has provided improved sensitivity but a lack of specificity in cervical and oral cavity studies $[109,111]$. In the oral cavity, sensitivities range between 84-100\%, and specificities range between $44-100 \%$, due to differences in methodology and sample type [111].

Recently we developed molecular-specific contrast agents for vital reflectance imaging [112,113]. The contrast agents are based on gold nanoparticles attached to probe molecules with high affinity for specific cellular biomarkers. Optical interrogation is based on the ability of the metal nanoparticles to scatter visible and near infrared (NIR) light resonantly; molecular specificity is determined by monoclonal antibodies. Gold bioconjugates provide, to our knowledge, the first molecular-specific source of contrast for reflectancebased imaging in living tissue.

Optical properties of silver and gold nanoparticles are determined by surface plasmon resonances in the metal particles that are extremely sensitive to such factors as a particle's size, shape, and aggregation state; dielectric properties of the surrounding medium; and adsorption of ions on the surface of the particles [114]. Harnessing the unique properties of the surface plasmon resonances has led to development of novel applications in biology and bioanalytical chemistry. Surface-enhanced Raman scattering (SERS) spectroscopy has been used to provide highly resolved vibrational information at the level of a single cell $[115,116]$ and a single molecule [117]. A highly selective colorimetric DNA probe technique, based on reversible assembly of oligonucleotide-capped gold colloid, showed a detection limit of about 10 femtomoles and sensitivity to a single base pair mismatch [118]. Gold nanoshell-polymer composites were proposed as a candidate for a photothermally triggered drug delivery system [119]. Aside from optically based applications, gold nanoparticles have been used extensively as molecular-specific stains in electron microscopy of cells and tissues [120,121]. In this field, the fundamental principles of interactions between the gold particles and biomolecules, especially proteins, have been thoroughly studied. Recently, the ability of metal nanoparticles to scatter visible light resonantly was explored in darkfield optical microscopy to probe adenosine triphosphate (ATP)-dependent rotation of a single F1-ATPase enzyme [122] and to perform in situ hybridization [123].

We developed bioconjugates of gold nanoparticles with anti-EGFR monoclonal antibodies to demonstrate molecular optical imaging in two biologically relevant samples: suspensions of epithelial cervical cancer cells ( $\mathrm{SiHa}$ ) and fresh tissue slices [104]. EGFR is a trans-membrane glycoprotein that is overexpressed in a vast majority of epithelial cancers [124]. Figure 16 shows $\mathrm{SiHa}$ cervical cancer cells labeled with gold particles/anti-EGFR monoclonal antibodies conjugates. The images were obtained using a reflectance confocal microscope with $800 \mathrm{~nm}$ laser excitation. Bright rings around the surface of the SiHa cells where the conjugates are bound can be seen clearly. No binding was observed with bovine serum albumin (BSA)/gold particles conjugates, and unlabeled cells could barely be resolved on dark background. The measurements were performed before and after washing the labeled cells from an excess of the conjugates in solution. No unbound single conjugates were visible in the sample either before or after washing. The conjugates are uniformly distributed on the surface of the cells.

It appears that conjugates closely spaced on the surface of epithelial cells scatter light more strongly than do isolated metal nanoparticles. This observation can be explained by the fact that interaction between closely 

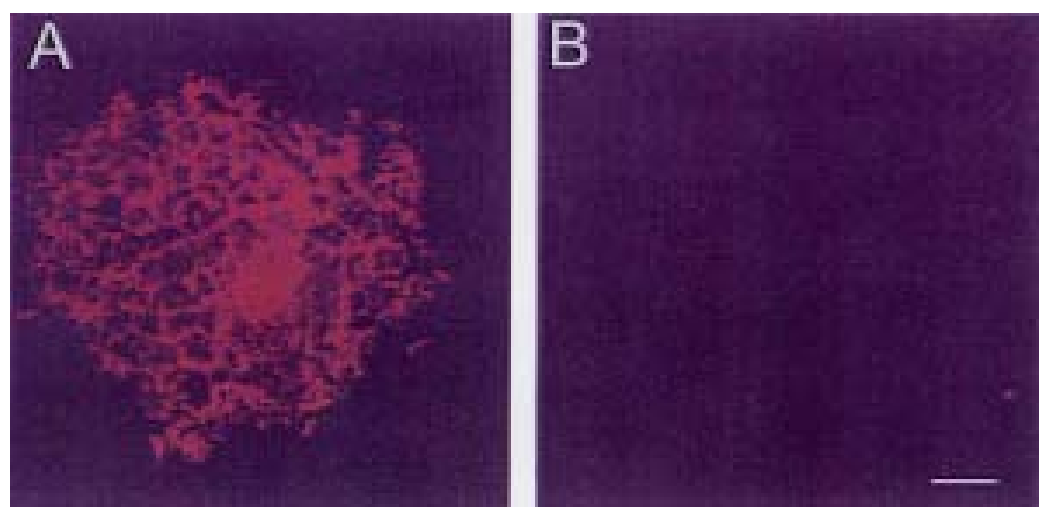

Fig. 17. Cervical biopsies labeled with anti-EGFR mAbs/gold nanoparticles conjugates: A. clinically abnormal; B. clinically normal obtained under the same acquisition conditions as $\mathrm{A}$.

spaced nanoparticles results in a red shift of their plasmon resonances as compared to the individual particles. The extinction of the assembly in the red optical region is significantly higher than the sum of the extinction of individual particles forming the assembly. Therefore, excitation and collection conditions potentially can be optimized to selectively detect closely spaced metal particles and their assemblies in the presence of the metal particles that are far apart. Application of this concept can allow additional increases in contrast between normal and cancerous epithelial cells because cancerous cells have significantly higher density of EGFR as compared to normal cells. The scattering of labeled SiHa cells is so strong that it can easily be observed using only a low magnification objective (10X or 20X) and a regular laser pointer as an illumination source [113].

We extended our work using anti-EGFR gold nanoparticle conjugates to label organ cultures of normal and neoplastic cervical tissue. To prepare fresh tissue slices, cervical biopsies were obtained, with written consent, from women seen in the University of Texas M.D. Anderson Cancer Center Colposcopy Clinic. Biopsies were placed immediately in chilled culture medium and then embedded in agarose. A Krumdieck Tissue Slicer was used to obtain 200-micron thick fresh tissue slices, which can be maintained alive in culture for 7-10 days. Slices were incubated in a solution containing the contrast agent, washed, and then imaged with reflectance-based confocal microscopy.

The bright "honeycomb"-like structure of labeled cellular cytoplasm membranes of closely spaced cells can be seen easily in clinically abnormal samples of cervical biopsies obtained using a confocal reflectance microscope (Fig. 17(A)). The labeling is much less pronounced in clinically normal samples. In fact, no label- ing of the normal biopsy can be seen when the sample is imaged under the same acquisition conditions as the abnormal sample (Fig. 17(B)). Anti-EGFR antibody/gold particle conjugates do not bind to the stromal layer of cervical biopsies.

\subsubsection{Fluorescence-based contrast agents}

Fluorescence-based contrast agents include compounds that affect endogenous fluorophores to increase the amount of autofluorescence as well as nonspecific dyes, target-specific conjugates, and fluorescent nanoparticles, which create artificial fluorescence signals in the sample. The most common compound used to increase the autofluorescence of tissue is 5aminolevulinic acid (ALA). The presence of ALA increases the endogenous concentration of protoporphyrin IX (PP IX), a native fluorescent porphyrin. PP IX excites in the blue region $(450 \mathrm{~nm})$ and emits in the red region $(620 \mathrm{~nm})$. In the presence of ALA, increased PP IX fluorescence has led to increased detection of dysplasia in ex vivo tissue from Barrett's esophagus and human urinary bladder tumors $[109,125]$.

The cyanine dyes are another class of non-specific fluorescent dyes. These dyes are popular because it is possible to create derivatives from the dyes that have absorption and fluorescence peaks throughout the visible and near-infrared regions [109]. Indocyanine green (ICG) is a near-infrared fluorescent dye. It has been used to study retinal and chorodial circulation for more than 30 years $[109,126,127]$ and recently has shown, in both animal and human studies, distinct perfusion in areas of dysplastic tissue due to the greater extravasation of the dye through leaky vasculature and rapid uptake by dysplastic tissue [128].

In the case of dysplastic tissue, localization of these dyes is mediated mainly by the leaky tumor vascula- 
ture. This makes it difficult to distinguish between areas of inflammation and injury and areas of benign and malignant tumor progression. Therefore, to increase tumor specificity for dysplastic tissue and molecular specificity in general, dyes have been conjugated to biomolecules that target unique factors in various disease states [109,128,129]. Target-specific conjugates combine a fluorescent molecule with a specific marker, such as an antibody or peptide, to yield molecular specificity in optical detection. Since cancers over-express certain receptors, a number of studies have concentrated on the conjugation of a fluorescent molecule to an antibody for a particular over-expressed receptor. To target human gastric cancer, for example, Ito et al. conjugated a mouse anti-human carcinoembryonic (CEA) antibody to indocyanine green $\mathrm{N}$ hydroxysulfosuccinimide ester (ICG-sulfo-OSu). Using fluorescence spectroscopy with an endoscope, the investigators were able to define regions of dysplasia in biopsy specimens from the stomach [130].

Some in vivo studies have shown, however, that large biomolecules such as antibodies circulate through the blood for prolonged periods of time, delaying visualization of the target tissue and triggering immune responses $[131,132]$. Therefore, some laboratories instead are connecting fluorescent molecules to small bioactive molecules, such as peptides, creating dyepeptide conjugates that are receptor specific [131-133]. A near-infrared dye-peptide conjugate has been created to target certain over-expressed tumor receptors in established rat tumor lines. Using a simple imaging system, Achilefu and colleagues found high uptake of the conjugates by the target tumors, showing successful tumor-specific targeting with the dyepeptide conjugate [131-133]. Tung et al. used a near-infrared dye-peptide conjugate to successfully target, in vivo, the folate receptor of ovarian cancer induced in nude mice [134], and Becker et al. used a near-infrared cyanine dye-peptide conjugate to specifically target RIN38/SSTR2 tumor cells in nude mouse xenografts [135].

Target-specific conjugates also include various nanoparticles, such as luminescent nanoparticles and quantum dots. The luminescent nanoparticles are non-toxic and biocompatible luminescent materials for cell staining and visualization. Santra et al. recently created a luminophore-doped silica nanoparticle attached to an antibody for leukemia-cell recognition that excites at $458 \mathrm{~nm}$ and fluoresces at $594 \mathrm{~nm}$. These particles have shown high sensitivity labeling in human cell suspensions [136].
Research on development of cancer-specific contrast agents still is in its early stages. Recent results, however, demonstrated the potential of the contrast agents to improve dramatically the sensitivity and selectivity of cancer detection, characterization, and monitoring. Contrast agents provide strong sources of signal that allow high-resolution micro-anatomic optical imaging of human tissue. Further development of molecularspecific contrast agents will allow visualization of the three-dimensional distribution of cancer-related molecular alterations in situ; this will be an invaluable asset in cancer monitoring, prognosis, and chemoprevention trials. Presently, only simple contrast agents that lack molecular specificity are used in clinical practice (e.g., acetic acid). Recent US Food and Drug Administration approvals of monoclonal antibodies for targeted therapeutic applications $[137,138]$, however, open new opportunities for clinical evaluation of molecular-specific contrast agents for high-resolution molecular imaging of cancers.

\section{Future improvements}

In vivo endoscopic optical microscopy provides a tool to assess tissue architecture and morphology with contrast and resolution similar to that provided by standard histopathology - without need for biopsy. As such, this emerging technology has the potential to improve dramatically the specificity of detection methods for early neoplastic lesions. Furthermore, in vivo high-resolution imaging has the potential to improve assessment of tumor margins and determination of response to chemotherapy or chemoprevention by providing quantitative architectural and morphologic images of a large number of sites throughout the organ surface area, without need for extensive tissue removal. Because optical images can be recorded remotely - in near real time without need for tissue removal - and image analysis can be automated, we believe that optical endoscopic imaging affords many important advantages over traditional techniques, including the potential to: (1) reduce the need for clinical expertise and reduce the number of unnecessary biopsies; (2) maximize the efficacy and reduce the morbidity of surgical treatment; (3) quickly assess whether a tumor is responding to a less morbid treatment such as chemotherapy; and (4) aid in the evaluation of chemopreventive agents. Current systems to record reflected light images in vivo have some important limitations, however. In general, small, flexible fiber optic devices with the necessary resolution 
and sensitivity to measure reflectance images of tissue are not available and have not been tested rigorously in clinical trials.

Specifically, for the distal scanning endoscope, bundles with fibers packed more closely are needed to reduce the effects of pixelation in confocal reflectance images. Also, miniature objectives are expensive to produce and assemble. Cost-effective methods for manufacturing larger quantities of miniature objectives are desirable to facilitate conducting clinical trials with various markers and development of commercial instruments. MEMS-based approaches for endoscopic confocal imaging show promise, but the feasibility of applying this approach to biological samples needs to be investigated.

While sub-cellular resolution has been demonstrated with tabletop OCT systems using expensive modelocked femtosecond lasers, resolution for endoscopic OCT systems continues to lag in this area, achieving axial and lateral resolutions of approximately $10 \mu \mathrm{m}$ and $30 \mu \mathrm{m}$, respectively [139]. Sources that combine the broad bandwidths and higher power of the specialized lasers with the lower priced, high reliability, and compact packaging needed for viable clinical systems are required. Also, research should continue to investigate improving lateral resolution either through dynamic focusing techniques or OCM. Feasibility studies, both in vitro and in vivo using an endoscope, should be performed to investigate whether OCM's performance benefits for imaging tissue will outweigh the increased complexity of the systems.

Another rapidly progressing area is the expansion of additional imaging modalities derived from the basic OCT system. The wealth of information in the interferometric signal that forms the basis of OCT makes polarization-sensitive, color Doppler, and spectroscopic versions possible. These modalities are capable of providing information on the change in cartilage due to osteoarthritis [140], blood flow in port wine stains during laser therapy [141], and increased contrast and differentiation over standard OCT images [30].

Development of molecular-specific contrast agents can give the reflectance vital optical microscopies the same impetus as fluorescent labels did for fluorescenceimaging modalities. The reflectance-based contrast agents can dramatically improve visualization of subcellular details in many tissue types deeper within the epithelium and enable molecular imaging of tissue pathology.

\section{Acknowledgments}

The authors acknowledge financial support from NIH (grants CA 82880 and PO1-CA82710) and NSF (BES-0119450).

\section{References}

[1] G. Dallen Bach-Hellueg and H. Doulson, Histopathology of the Cervix Uteri, Springer-Verlag, New York Inc., 1990.

[2] D. Huang et al., Optical coherence tomography, Science 254 (1991), 1178-1181.

[3] M. Rajadhyaksha, M. Grossman, D. Esterowitz, R.H. Webb and R.R. Anderson, In vivo confocal scanning laser microscopy of human skin: melanin provides strong contrast, $J$ Invest Dermatol 104 (1995), 946-952.

[4] C. Liang, K. Sung, R. Richards-Kortum and M.R. Descour, Fiber confocal reflectance microscope (FCRM) for in-vivo imaging, Opt Express 9 (2001), 821-830.

[5] G.J. Tearney et al., In vivo endoscopic optical biopsy with optical coherence tomography, Science 276 (1997), 20372039.

[6] R. Juskaitis, F. Reinholz and T. Wilson, Fibre-optic based confocal scanning microscopy with semiconductor laser excitation and detection, Electron Lett 28 (1992), 986-988.

[7] R. Juskaitis and T. Wilson, Direct view fiber optic confocal microscope, Opt Lett 19 (1994), 1906-1908.

[8] J. Benschop and G. van Rosmalen, Confocal compact scanning optical microscope based on compact disc technology, Appl Opt 30 (1991), 1179-1184.

[9] G.J. Tearney, R.H. Webb and B.E. Bouma, Spectrally encoded confocal microscopy, Opt Lett 23 (1998), 1152-1154.

[10] L. Giniunas, R. Juskaitis and S.V. Shatalin, Scanning fibreoptic microscope, Electron Lett 27 (1991), 724-726.

[11] D.L. Dickensheets and G.S. Kino, A scanned optical fiber confocal microscope, Proceedings of SPIE 2184 (1994), 3947.

[12] D.L. Dickensheets and G.S Kino, Silicon-micromachined scanning confocal optical microscope, J Microelectromech $S$ 7 (1998), 38-47.

[13] A.F. Gmitro and D. Aziz, Confocal microscopy through a fiber-optic imaging bundle, Opt Lett 18 (1993), 565-567.

[14] R. Juskaitis, T. Wilson and T.F. Watson, Real-time white light reflection confocal microscopy using a fibre-optic bundle, Scanning 19 (1997), 15-19.

[15] K.B. Sung, C. Liang, M. Descour, T. Collier, M. Follen and R. Richards-Kortum, Near real time in vivo fiber optic confocal microscopy: sub-cellular structure resolved, J Microsc 207 (2002), 137-145.

[16] C.P. Lin and R.H. Webb, Fiber coupled multiplexed confocal microscope, Opt Lett 25 (2000), 954-956.

[17] P. Lane, A. Dlugan and C. MacAulay, DMD-enabled confocal microendoscopy, coherence domain optical methods in biomedical science and clinical applications V, Proceedings of SPIE 4251 (2001), 192-198.

[18] Y.S. Sabharwal, A.R. Rouse, L. Donaldson, M.F. Hopkins and A.F. Gmitro, Slit-scanning confocal microendoscope for high-resolution in vivo imaging, Appl Opt 38 (1999), 71337144.

[19] W. Drexler, U. Morgner, F.X. Kartner, C. Pitris, S.A. Boppart, X.D. Li, E.P. Ippen and J.G. Fujimoto, In vivo ultrahigh- 
resolution optical coherence tomography, Opt Lett 24 (1999), 1221-1223.

[20] J.M. Schmitt, Optical coherence tomography (OCT): a review, IEEE J Sel Top Quan 5 (1999), 1205-1215.

[21] M.E. Brezinski, G.J. Tearney, B.E. Bouma, J.A. Izatt, M.R. Hee, E.A. Swanson, J.F. Southern and J.G. Fujimoto, Optical coherence tomography for optical biopsy, Circulation (1996), 1206-1213.

[22] B.E. Bouma and G.J. Tearney, Power-efficient nonreciprocal interferometer and linear-scanning fiber-optic catheter for optical coherence tomography, Opt Lett 24 (1999), 531-533.

[23] G. Zuccaro, N. Gladkova, J. Vargo, F. Feldchtein, E. Zagaynova, D. Conwell, G. Falk, J. Goldblum, J. Dumot, J. Ponsky, G. Gelikonov, B. Davros, E. Donchenko and J. Richter, Optical coherence tomography of the esophagus and proximal stomach in health and disease, Am J Gastroenterol 96 (2001), 2633-2639.

[24] A.M. Rollins, R. Ung-Arunyawee, A. Chak, R.C.K. Wong, K. Kobayashi, M.V. Sivak and J.A. Izatt, Real-time in vivo imaging of human gastrointestinal ultrastructure by use of endoscopic optical coherence tomography with a novel efficient interferometer design, Opt Lett 24 (1999), 1358-1360.

[25] G.J. Tearney, S.A. Boppart, B.E. Bouma, M.E. Brezinski, N.J. Weissman, J.F. Southern and J.G. Fujimoto, Scanning single-mode fiber optic catheter-endoscope for optical coherence tomography, Opt Lett 21 (1996), 543-545.

[26] A. Das, M.V. Sivak, Jr., A. Chak, R.C. Wong, V. Westphal, A.M. Rollins, J. Willis, G. Isenberg and J.A. Izatt, High-resolution endoscopic imaging of the GI tract: a comparative study of optical coherence tomography versus high-frequency catheter probe EUS, Gastrointest Endosc $\mathbf{5 4}$ (2001), 219-224.

[27] S. Jäckle, N. Gladkova, F. Feldchtein, A. Terentieva, B. Brand, G. Gelikonov, V. Gelikonov, A. Sergeev, A. FritscherRavens, J. Freund, U. Seitz, S. Soehendra and N. Schrödern, In vivo endoscopic optical coherence tomography of the human gastrointestinal tract - toward optical biopsy, Endoscopy 32 (2000), 743-749.

[28] A.M. Rollins, V. Westphal, A. Das, P. Pfau, A. Chak, R.C.K. Wong, M.V. Sivak and J.A. Izatt, In situ visualization and evaluation of neoplastic lesions of the human gastrointestinal tract using endoscopic optical coherence tomography, Proceedings of SPIE - The International Society for Opt Eng 4254 (2001).

[29] S. Jäckle, N. Gladkova, F. Feldchtein, A. Terentieva, B. Brand, G. Gelikonov, V. Gelikonov, A. Sergeev, A. FritscherRavens, J. Freund, U. Seitz, S. Schröder and N. Soehendra, In vivo endoscopic optical coherence tomography of esophagitis, Barrett's esophagus, and adenocarcinoma of the esophagus, Endoscopy 32 (2000), 750-755.

[30] X.D. Li, S.A. Boppart, J. Van Dam, H. Mashimo, M. Mutinga, W. Drexler, M. Klein, C. Pitris, M.L. Krinsky, M.E. Brezinski and J.G. Fujimoto, Optical coherence tomography: advanced technology for the endoscopic imaging of Barrett's esophagus, Endoscopy 32 (2000), 921-930.

[31] M. Gupta, A.M. Rollins, J.A. Izatt and I.R. Efimov, Imaging of the atrioventricular node using optical coherence tomography, J Cardiovasc Electrophysiol 13 (2002), 95.

[32] A.M. Sergeev, V.M. Gelikonov, G.V. Gelikonov, F.I. Feldchtein, R.V. Kuranov and N.D. Gladkova, In vivo endoscopic OCT imaging of precancer and cancer states of human mucosa, Opt Express 1 (1997), 432-440.

[33] F.I. Feldchtein, G.V. Gelikonov, V.M. Gelikonov, R.V. Kuranov, A.M. Sergeev, N.D. Gladkova, N.M. Shakhova, M.
Shakhova, L.B. Snopova, A.B. Terent'eva, E.V. Zagainova, Y.P. Chumakov and I.A. Kuznetzova, Endoscopic applications of optical coherence tomography, Opt Express 3 (1998), 257-270.

[34] M.N. Ourutina, N.D. Gladkova, F.I. Feldchtein, G.V. Gelikonov, V.M. Gelikonov, R.V. Kuranov and A.M. Sergeev, In vivo optical coherent tomography of teeth and oral mucosa, Proceedings of SPIE - The International Society for Optical Engineering 3567 (1999), 97-107.

[35] A.F. Zuluaga, M. Follen-Mitchell and R. Richards-Kortum, In vivo optical coherence tomography measurements in the cervix using a fiber optic probe, in: Conference on Lasers and Electro-Optics Europe - Technical Digest, IEEE, San Francisco, CA, 1998.

[36] B.W. Colston, Jr., U.S. Sathyam, L.B. DaSilva and M.J. Everett, Dental OCT, Opt Express 3 (1998), 230-234.

[37] J.K. Barton, D.B. Dal Ponte, S.K. Williams, B. Ford and M.R. Descour, Imaging vascular implants with optical coherence tomography, in: Conference on Coherence Domain Optical Methods in Biomedical Science and Clinical Applications $I V$, (Vol. 3915), Society of Photo-Optical Instrumentation Engineers, San Jose, CA, 2000, pp. 229-236.

[38] J.A. Izatt, M.D. Kulkarni, H.-W. Wang, K. Kobayashi and M.V. Sivak, Optical coherence tomography and microscopy in gastrointestinal tissues, IEEE J Sel Top Quan 2 (1996), 1017-1028.

[39] M. Bashkansky, M.D. Duncan, M. Kahn, D. Lewis, III and J. Reintjes, Subsurface defect detection in ceramics by highspeed high-resolution optical coherence tomography, Opt Lett 22 (1997), 61-63.

[40] M. Bashkansky and J. Reintjes, Statistics and reduction of speckle in optical coherence tomography, Opt Lett 25 (2000), 545-547.

[41] E. Beaurepaire, A.C. Boccara, M. Lebec, L. Blanchot and H. Saint-James, Full-field optical coherence microscopy, Opt Lett 23 (1998), 244-246.

[42] A.G. Podoleanu, G.M. Dobre and D.A. Jackson, En-face coherence imaging using galvanometer scanner modulation, Opt Lett 23 (1998), 147-149.

[43] A.G. Podoleanu, J.A. Rogers and D.A. Jackson, OCT en-face images from the retina with adjustable depth resolution in real time, IEEE J Sel Top Quan 5 (1999), 1176-1184.

[44] A.G. Podoleanu, J.A. Rogers and D.A. Jackson, Three dimensional OCT images from retina and skin, Opt Express 7 (2000), 292-298.

[45] A.G. Podoleanu, M. Seeger, G.M. Dobre, D.J. Webb, D.A. Jackson and F.W. Fitzke, Transversal and longitudinal images from the retina of the living eye using low coherence reflectometry, J Biomed Opt 3 (1998), 12-20.

[46] F. Xu, H.E. Pudavar, P.N. Prasad and D. Dickensheets, Confocal enhanced optical coherence tomography for nondestructive evaluation of paints and coatings, Opt Lett 24 (1999), 1808-1810.

[47] E. Beaurepaire, L. Moreaux, F. Amblard and J. Mertz, Combined scanning optical coherence and two-photon-excited fluorescence microscopy, Opt Lett 24 (1999), 969-971.

[48] J.M. Schmitt, S.L. Lee and K.M. Yung, An optical coherence microscope with enhanced resolving power in thick tissue, Opt Commun 142 (1997), 203-207.

[49] J.A. Izatt, M.R. Hee and G.M. Owen, Optical coherence microscopy in scattering media, Opt Lett 19 (1994), 590.

[50] H.W. Wang, A.M. Rollins and J.A. Izatt, High speed, full field optical coherence microscopy, in: Conference on Coherence Domain Optical Methods in Biomedical Science and Clin- 
ical Applications III, (Vol. 3598), Society of Photo-Optical Instrumentation Engineers, Bellingham, WA, 1999, pp. 204212.

[51] B.M. Hoeling, A.D. Fernandez, R.C. Haskell, E. Huang, W.R. Myers, D.C. Peterson, S.E. Ungersma, R. Wang and M.E. Williams, An optical coherence microscope for 3dimensional imaging in developmental biology, Opt Express 6 (2000), 136-146.

[52] J.W. Hettinger, M. de la Pena Mattozzi, W.R. Myers, M.E. Williams, A. Reeves, R.L. Parsons, R.C. Haskell, R. Wang and J.I. Medford, Optical coherence microscopy. a technology for rapid, in vivo, non-destructive visualization of plants and plant cells, Plant Physiol 123 (2000), 3-15.

[53] M. Rajadhyaksha, S. Gonzalez, J. Zavislan, R.R. Anderson and R.H. Webb. In vivo confocal scanning laser microscopy of human skin II: advances in instrumentation and comparison with histology, I Invest Dermatol 104 (1999), 946-952.

[54] W.M. White, M. Ragadhyaksha, S. Gonzalez, R.L. Fabian and R.R. Anderson, Noninvasive imaging of human oral mucosa in vivo by confocal reflectance microscopy, Laryngoscope 109 (1999), 1709-1717.

[55] R. Drezek, T. Collier, C. Brookner, A. Malpica, R. Lotan and R. Richards-Kortum, Laser scanning confocal microscopy of cervical tissue before and after application of acetic acid, $A m$ J Obstet Gynecol 182 (2000), 1135-1139.

[56] H. Inoue, I. Igari, T. Nishikage, K. Ami, T. Yoshida and T. Iwai, A novel method of virtual histopathology using laser scanning confocal microscopy in vitro with untreated fresh specimens from the GI mucosa, Endoscopy 32 (2000), 439443.

[57] C. Betrand and B. Corcuff, In vivo spatio-temporal visualization of the human skin by real-time confocal microscopy, Scanning 16 (1994), 150-154.

[58] P. Corcuff, G. Gonnord, G.E. Pierard and J.L. Leveque, In vivo confocal microscopy of human skin: a new design from cosmetology and dermatology, Scanning 18 (1996), 351355 .

[59] B.R. Masters, D.J. Aziz, A.F. Gmitro, J.H. Kerr, T.C. O’Grady and L. Goldman, Rapid observation of unfixed unstained human skin biopsy specimens with confocal microscopy and visualization, J Biomed Opt 2 (1997), 437-445.

[60] S. Gonzalez, E. Gonzalez, M. White, M. Rajadhyaksha and R.R. Anderson, Allergic contact dermatitis: correlation of in vivo confocal imaging to routine histology, J Am Acad Dermatol 40 (1999), 708-713.

[61] D. Aghassi, R.R. Anderson and S. Gonzalez, Confocal laser microscopic imaging of actinic keratoses in vivo: a preliminary report, J Am Acad Dermatol 43 (2000), 42-48.

[62] W. Hongcharu, P. Dwyer, S. Gonzalez and R.R. Anderson, Confirmation of onychomycosis by in vivo confocal microscopy, J Am Acad Dermatol 42 (2000), 214-216.

[63] S. Gonzalez, M. Rajadhyaksha, G. Rubinstein and R.R. Anderson, Characterization of psoriasis in vivo by reflectance confocal microscopy, J Med 30 (1999), 337-356.

[64] S. Gonzalez, G. Rubinstein, V. Mordovtseva, M. Rajadhyaksha and R.R. Anderson, In vivo abnormal keratinziation in Darier' White's disease as viewed by real time confocal imaging, J Cutan Pathol 26 (1999), 504-508.

[65] D. Aghassi, E. Gonzalez, R.R. Anderson, M. Rajadhyaksha and S. Gonzalez, Elucidating the pulsed dye laser treatment of sebaceous hyperplasia in vivo with real time confocal scanning laser microscopy, J Am Acad Dermatol 43 (2000), 49-53.
[66] S. Gonzalez, W.M. White, M. Rajadhyaksha, R.R. Anderson and E. Gonzalez, Confocal imaging of sebaceous gland hyperplasia in vivo to assess efficacy and mechanism of pulsed dye laser treatment, Laser Surg Med 25 (1999), 8-12.

[67] D. Aghassi, R.R. Anderson and S. Gonzalez, Time sequence histology imaging of laser treated cherry angiomas with in vivo confcal microscopy, J Am Acad Dermatol 43 (2000), 37-41.

[68] S. Gonzalez, M. Rajadhyaksha, A. Gonzaelz-Serva, M.W. White and R.R. Anderson, Confocal reflectance imaging of folliculitis in vivo: correlation with routine histology, J Cutan Pathol 26 (1999), 201-205.

[69] K.J. Busam, K. Hester, C. Charles, D.L. Sachs, C.R. Antonescu, S. Gonzalez and A. Halpern, Detection of clinically amelanotic malignant melanoma and assessment of its margins by in vivo confocal scanning laser microscopy, Arch Dermatol 137 (2001), 923-929.

[70] R.G.B. Langley, M. Rajadhyaksha, P.J. Dwyer, A.J. Sober, T.J. Flotte and R.R. Anderson, Confocal scanning laser microcopy of benign and malignancy melanocytic skin lesions in vivo, J Am Acad Dermatol 45 (2001), 365-376.

[71] M. Rajadhyaksha, R.R. Anderson and R.H. Webb, Videorate confocal scanning laser microscope for imaging human tissues in vivo, Appl Opt 38 (1999), 2105-2115.

[72] T. Collier, A. Lacy, R. Richards-Kortum, A. Malpica and M. Follen, Near real time confocal microscopy of amelanotic tissue: detection of dysplasia in ex-vivo cervical tissue, Acad Radiol 9 (2002), 504-512.

[73] X. Gan, M. Gu and C.J.R. Sheppard, Fluorescent image formation in the fibre optical confocal scanning microscope, $J$ Mod Opt 39 (1992), 825-834.

[74] P.M. Delaney, M.R. Harris and R.G. King, Fiber optic laser scanning confocal microscopy suitable for fluorescence imaging, Appl Opt 33 (1994), 573-577.

[75] J. Knittel, L. Schneider, G. Buess, B. Messerschmidt and T. Possner, Endoscope compatible confocal microscope using a gradient index lens system, Opt Commun 188 (2001), 267273.

[76] B.E. Bouma, G.J. Tearney, C.C. Compton and N.S. Nishioka, High-resolution imaging of the human esophagus and stomach in vivo using optical coherence tomography, Gastrointest Endosc 51(4 Pt 1) (2000), 467-474.

[77] J.M. Schmitt, A. Knüttel and M. Yadlowsky, Confocal microscopy in turbid media, J Opt Soc Am A: Optics, Image Science, and Vision 11 (1994), 2226-2235.

[78] M. Kempe and W. Rudolph, Analysis of heterodyne and confocal microscopy for illumination with broad-bandwidth light, J Mod Optic 43 (1996), 2189-2204.

[79] M. Kempe, W. Rudolph and E. Welsh, Comparative study of confocal and heterodyne microscopy for imaging through scattering media, J Opt Soc Am A: Optics, Image Science, and Vision 13 (1996), 46-52.

[80] A.K. Dunn, C. Smithpeter, A.J. Welch and R. RichardsKortum, Sources of contrast in confocal reflectance imaging, Appl Opt 35 (1996), 3441-3446.

[81] C.L. Smithpeter, A.K. Dunn, A.J. Welch and R. RichardsKortum, Penetration depth limits of in vivo confocal reflectance imaging, Appl Opt 37 (1998), 2749-2754.

[82] A. Baumgartner, C.K. Hitzenberger, H. Sattmann, W. Drexler and A.F. Fercher, Signal and resolution enhancements in dual beam optical coherence tomography of the human eye, $J$ Biomed Opt 3 (1998), 45-54.

[83] Y.J. Rao, Y.N. Ning and D.A. Jackson, Synthesized source for white-light sensing systems, Opt Lett 18 (1993), 462-464. 
[84] Y. Zhang, M. Sato and N. Tanno, Resolution improvement in optical coherence tomography by optimal synthesis of lightemitting diodes, Opt Lett 26 (2001), 205-207.

[85] I. Hartl, X.D. Li, C. Chudoba, R.K. Ghanta, T.H. Ko, J.G. Fujimoto, J.K. Ranka and R.S. Windeler, Ultrahigh-resolution optical coherence tomography using continuum generation in an air silica microstructure optical fiber, Opt Lett 26 (2001), 608-611.

[86] A.F. Fercher, C.K. Hitzenberger, M. Sticker, E. MorenoBarriuso, R. Leitgeb, W. Drexler and H. Sattmann, Thermal light source technique for optical coherence tomography, Opt Commun 185 (2000), 57-64.

[87] M.D. Kulkarni, C.W. Thomas and J.A. Izatt, Image enhancement in optical coherence tomography using deconvolution, Electron Lett 33 (1997), 1365-1367.

[88] R.K. Wang, Resolution improved optical coherence-gated tomography for imaging through biological tissues, J Mod Optic 46 (1999), 1905-1912.

[89] Z. Chen, Y. Zhao, S.M. Srinivas, J.S. Nelson, N. Prakash and R.D. Frostig, Optical doppler tomography, IEEE J Sel Top Quan 5 (1999), 1134-1142.

[90] F. Lexer, C.K. Hitzenberger, W. Drexler, S. Molebny, H. Sattmann, M. Sticker and A.F. Fercher, Dynamic coherent focus OCT with depth-independent transversal resolution, $J$ Mod Optic 46 (1999), 541-553.

[91] C.W. Boone, G.J. Kelloff and V.E. Steele, Natural history of intraepithelial neoplasia in humans with implications for cancer chemoprevention strategy, Cancer Res 52 (1992), 16511659.

[92] C.W. Boone, J.W. Bacus, J.V. Bacus, V.E. Steele and G.J. Kelloff, Properties of intraepithelial neoplasia relevant to cancer chemoprevention and to the development of surrogate end points for clinical trials, Proc Soc Exp Biol Med 216 (1997), 151-165.

[93] J.L. Schwartz, Biomarkers and molecular epidemiology and chemoprevention of oral carcinogenesis, Crit Rev Oral Biol Med 11(1) (2000), 92-122.

[94] T. Meyer and G.J. Rustin, Role of tumour markers in monitoring epithelial ovarian cancer, Br J Cancer 82(9) (2000), 1535-1538.

[95] I. Ramzy, Essentials of Gynecologic and Obstetric Pathology, Appleton-Century-Crofts, Norwalk, 1983.

[96] J. Thiran and B. Macq, Morphological feature extraction for the classification of digital images of cancerous tissues, IEEE T Bio-med Eng 43(10) (1996), 1011-1020.

[97] L.G. Koss, Diagnostic Cytology and Its Histopathologic Bases, J.B. Lippincott Company, Philadelphia, 1992.

[98] A. Taflove, Computational Electrodynamics: The FiniteDifference Time-Domain Method, Artech House, Norwood, 1995.

[99] A. Taflove (ed.), Advances in Computational Electrodynamics: The Finite-Difference Time-Domain Method, Artech House, Norwood, 1998.

[100] R. Drezek, M. Guillaud, T. Collier, I. Boiko, A. Malpica, C. MacAulay, M. Follen and R. Richards-Kortum, Light scattering from cervical cells throughout neoplastic progression: influence of nuclear morphology, DNA content, and chromatin texture, J Bio-med Opt (2002), in press.

[101] D. Arifler, Modeling light scattering from cells using the finite-difference time-domain method with a perfectly matched layer boundary condition, MS Thesis, Biomedical Engineering Department, The University of Texas, Austin, Texas, 2002.
[102] M. Guillaud, A. Doudkine, D. Garner, C. MacAulay and B. Palcic, Malignancy associated changes in cervical smears: systematic changes in cytometric features with the grade of dysplasia, Anal Cell Pathol 9(3) (1995), 191-204.

[103] R. Richards-Kortum and E. Sevick-Muraca, Quantitative optical spectroscopy for tissue diagnosis, Аnпu Rev Phys Chem 47 (1996), 555-606.

[104] R. Drezek, C. Brookner, I. Pavlova, I. Boiko, A. Malpica, R. Lotan, M. Follen and R. Richards-Kortum, Autofluorescence microscopy of fresh cervical-tissue sections reveals alterations in tissue biochemistry with dysplasia, Photochem Photobiol 73(6) (2001), 636-641.

[105] K. Akiba and N. Nakamura, Isolation and characterization of fluorescent material in bovine Achilles tendon collagen, Biochem Bioph Res Co 76 (1977), 1124-1129.

[106] C. Smithpeter, A. Dunn, R. Drezek, T. Collier and R. Richards-Kortum, Near real time confocal microscopy of cultured amelanotic cells: sources of signal, contrast agents and limits of contrast, J Biomed Opt 3(4) (1998), 429-436.

[107] T. Collier, P. Shen, B. de Pradier, K.B. Sung and R. RichardsKortum, Near real time confocal microscopy of amelanotic tissue: dynamics of aceto-whiting enable nuclear segmentation, Opt Express 6(2) (2000), 40-48.

[108] J.K. Barton, J.B. Hoying and C.J. Sullivan, Use of microbubbles as an optical coherence tomography contrast agent, Acad Radiol 9(Supplement 1) 9(2002), S52-S55.

[109] D.J. Bornhop, C.H. Contag, K. Licha and C.J. Murphy, Advances in contrast agents, reporters, and detection, J Biomed Opt 6(2) (2001), 106-110.

[110] K.A.A.S. Warnakulasuriya and N.W. Johnson, Sensitivity and specificity of OraScan toluidine blue mouthrinse in the detection of oral cancer and precancer, J Oral Pathol Med $\mathbf{2 5}$ (1996), 97-103.

[111] M.A. Onofre, M.R. Sposto and C.M. Navarro, Reliability of toluidine blue application in the detection of oral epithelial dysplasia and in situ and invasive squamous cell carcinomas, Oral Surg Oral Med Oral Pathol 91(5) (2001), 535-540.

[112] K. Sokolov, C. Robinson, T. Collier, M. Follen, R. Lotan and R. Richards-Kortum, Metal nanoparticles as biospecific contrast agents for cancer imaging. Presented at OSA Biomedical Topical Meeting on Biomedical Optical Spectroscopy and Diagnostics 7-10 April (2002), Miami Beach, Florida.

[113] K. Sokolov, M. Follen, J. Aaron, I. Pavlova, A. Malpica, R. Lotan and R. Richards-Kortum, Gold Nanoparticles as Molecular Specific Contrast Agents for Real Time Vital Optical Imaging, PNAS (2002), submitted.

[114] P. Mulvaney, Surface plasmon spectroscopy of nanosized metal particles, Langmuir 12 (1996), 788-800.

[115] I. Nabiev., K. Sokolov and M. Manfait, Surface enhanced raman spectroscopy and its biomedical applications, in: Biomolecular Spectroscopy, (Vol. 20), R.J.H. Clark and R.A. Hester, eds, Chichester, New York, Brisbane, Toronto, Singapore: John Wiley \& Sons, 1993, pp. 267-338.

[116] I.R. Nabiev, H. Morjani and M. Manfait, Selective analysis of antitumor drug interaction with living cancer cells as probed by surface-enhanced Raman spectroscopy, Eur Biophys $J$ 19(6) (1991), 311-316.

[117] S. Nie and S.R. Emory, Probing single molecules and single nanoparticles by surface-enhanced Raman scattering, Science 275 (1997), 1102-1106.

[118] R. Elghanian, J.J. Storhoff, R.C. Mucic, R.L. Letsinger and C.A. Mirkin, Selective colorimetric detection of polynucleotides based on the distance-dependent optical properties of gold nanoparticles, Science 277 (1997), 1078-1081. 
[119] S.R. Sershen, S.L. Westcott, N.L. Halas and J.L. West, Temperature-sensitive polymer-nanoshell composites for photothermally modulated drug delivery, J Biomed Mater Res 51(3) (2000)

[120] M. Horisberger, Colloidal gold: a cytochemical marker for light and fluorescent microscopy and for transmission and scanning electron microscopt, Scan Electron Micros 11 (1981), 9-31

[121] W.D. Geoghegan and G.A. Ackerman, Adsorption of horseradish peroxidase, ovomucoid and anti-immunoglobulin to colloidal gold for the indirect detection of concanavalin A, wheat germ agglutination and goat anti-human immunoglobulin $\mathrm{G}$ on cell surface at the electron microscope level: a new method, theory and application, J Histochem Cytochem 25 (1977), 1187-1200.

[122] R. Yasuda, H. Noji, M. Yoshida, K. Kinosita and H. Itoh, Resolution of distinct rotational substeps by submillisecond kinetic analysis of F1-ATPase, Nature 410 (2001), 898-904.

[123] S. Schultz, D. Smith, J. Mock and D. Schultz, Single-target molecule detection with nonbleaching multicolor optical immunolabels, Proc Natl Acad Sci USA 97(3) (2000), 9961001.

[124] G. Carpenter, Receptors for epidermal growth factor and other polypeptide mitogens, Ann Rev Biochem 56 (1987), 881-914.

[125] M. Lipinski and L. Jeromin, Comparison of the bladder tumor antigen test with photodynamic diagnosis in patients with pathologically confirmed recurrent superficial urinary bladder tumors, BJU Int 89(7) (2002), 757-759.

[126] T. Desmettre, J.M. Devoisselle and S. Mordon, Fluorescence properties and metabolic features of indocyanine green (ICG) as related to angiography, Surv Ophthalmol 45(1) (2000), 15-27.

[127] J.S. Slakter, L.A. Yannuzzi, D.R. Guyer, J.A. Sorenson and D.A. Orlock, Indocyanine-green angiography, Curr Opin Ophthalmol 6(3) (1995), 25-32.

[128] M.M. Haglund, M.S. Berger and D.W. Hochman, Enhanced optical imaging of human gliomas and tumor margins, $\mathrm{Neu}$ rosurgery $\mathbf{2 8}(2)$ (1996).

[129] S.I. Achilefu, R.B. Dorshow, J.E. Bugaj and R. Rajagopalan, Tumor-specific contrast agents, Proceedings of SPIE: Optical Biopsy III 3917 (2000), 80-86.

[130] S. Ito, N. Muguruma, Y. Kusaka, M. Tadatsu, K. Inayama, Y. Musashi, M. Yano, T. Bando, H. Honda, I. Shimizu, K. Li, K. Takesako, H. Takeuchi and S. Shibamura, Detection of human gastric cancer in resected specimens using a novel infrared fluorescent anti-human carcinoembryonic antigen antibody with an infrared fluorescence endoscope in vitro, Endoscopy 33(10) (2001), 849-853.

[131] S.I. Achilefu, J.E. Bugaj, R.B. Dorshow, H.N. Jimenez, R. Rajagopalan, R.R. Wilhelm, E.G. Webb and J.L. Erion, Sitespecific tumor-targeted fluorescent contrast agents, Proceedings of SPIE: Clinical Lasers and Diagnostics 4156 (2001), 69-78.

[132] S.I. Achilefu, J.E. Bugaj, R.B. Dorshow, H.N. Jimenez and R. Rajagopalan, New approach to optical imaging of tumors, Proceedings of SPIE: Biomarkers and Biological Spectral Imaging 4259 (2001), 110-114.

[133] J.E. Bugaj, S.I. Achilefu, R.B. Dorshow, H.N. Jimenez and R. Rajagopalan, Novel fluorescent contrast agents for optical imaging of in vivo tumors based on a receptor-targeted dyepeptide conjugate platform, J Biomed Opt 6(2) (2001), 122133.

[134] C.H. Tung, Y. Lin, W.K. Moon and R. Weissleder, A receptortargeted near-infrared fluorescence probe for in vivo tumor imaging, ChemBioChem 8 (2002), 784-786.

[135] A. Becker, C. Hessenius, K. Licha, B. Ebert, U. Sukowski, W. Semmler, B. Wiedenmann and C. Grotzinger, Receptortargeted optical imaging of tumors with near-infrared fluorescent ligands, Nat Biotechnol 19 (2001), 327-331.

[136] S. Santra, P. Zhang, K. Wang, R. Tapec and W. Tan, Conjugation of biomolecules with luminophore-doped silica nanoparticles for photostable biomarkers, Anal Chem 73(20) (2001), 4988-4993.

[137] P. Holliger and H. Bohlen, Engineering antibodies for the clinic, Canc Metastas Rev 18(4) (1999), 411-419.

[138] L.M. Weiner, Monoclonal antibody therapy of cancer, Semin Oncol 26(5 Suppl 14) (Oct 1999), 43-51.

[139] S. Brand, J.M. Ponero, B.E. Bouma, G.J. Tearney, C.C. Compton and N.S. Nishioka, Optical coherence tomography in the gastrointestinal tract, Endoscopy 32 (2000), 796-803.

[140] W. Drexler, D. Stamper, C. Jesser, X. Li, C. Pitris, K. Saunders, S. Martin, M.B. Lodge, J.G. Fujimoto and M.E. Brezinski, Correlation of collagen organization with polarization sensitive imaging of in vitro cartilage: implications for osteoarthritis, J Rheumatol 28 (2001), 1311-1318.

[141] J.S. Nelson, K.M. Kelly, Y. Zhao and Z. Chen, Imaging blood flow in human port-wine stain in situ and in real time using optical Doppler tomography, Arch Dermatol 137 (2001), 741-744. 


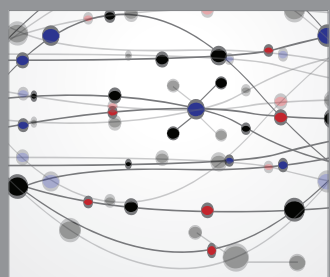

The Scientific World Journal
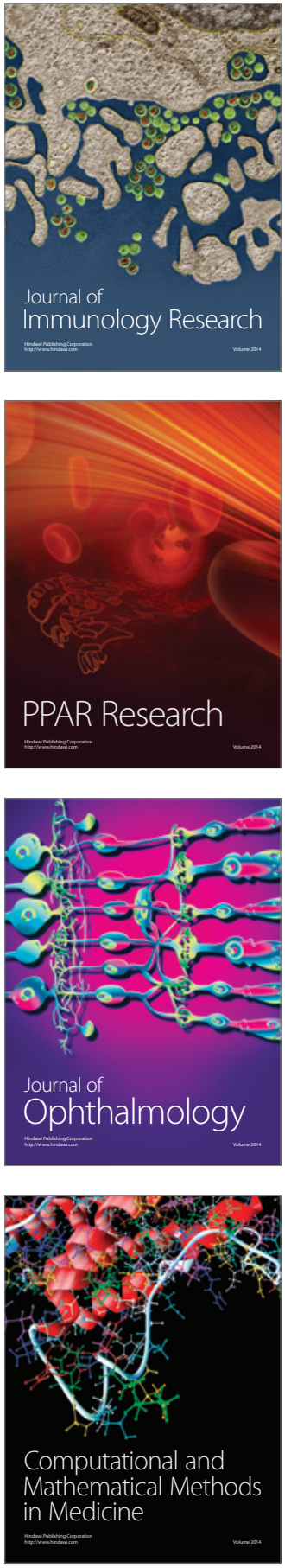

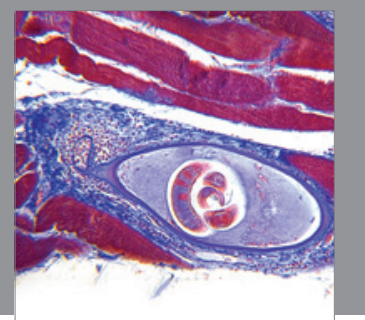

Gastroenterology

Research and Practice
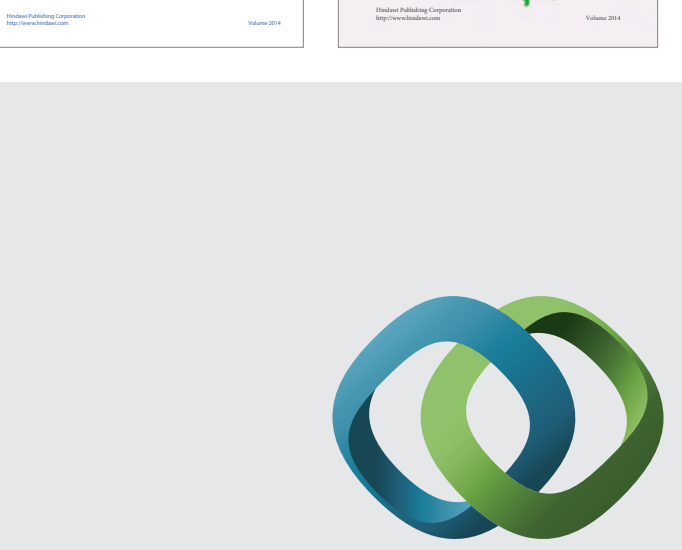

\section{Hindawi}

Submit your manuscripts at

http://www.hindawi.com
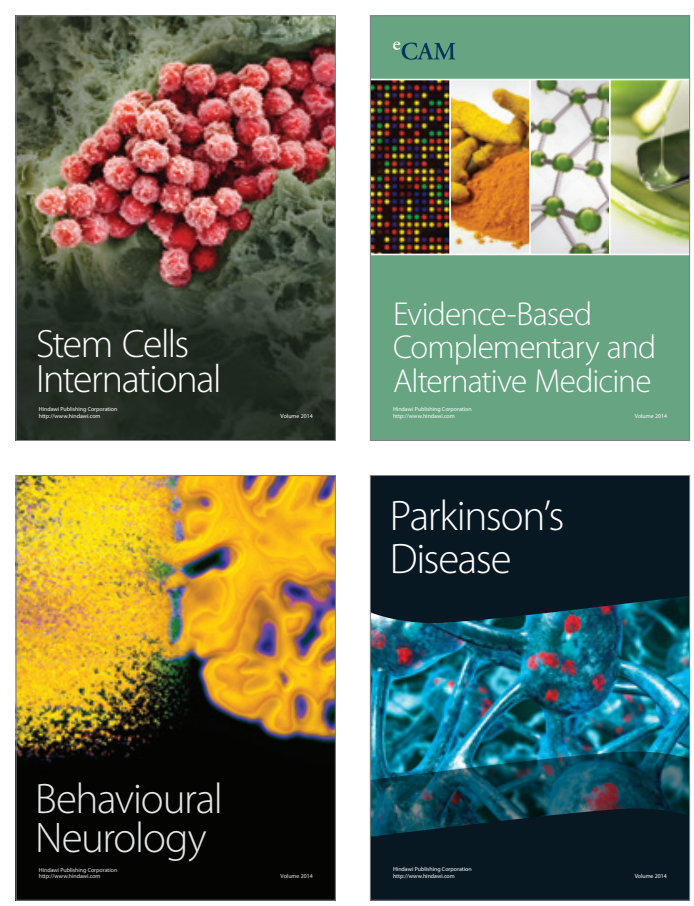

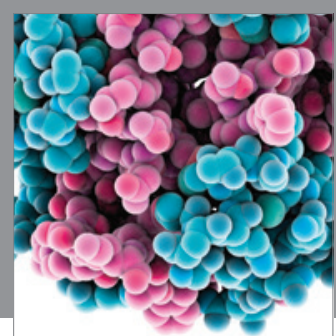

Journal of
Diabetes Research

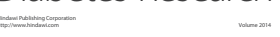

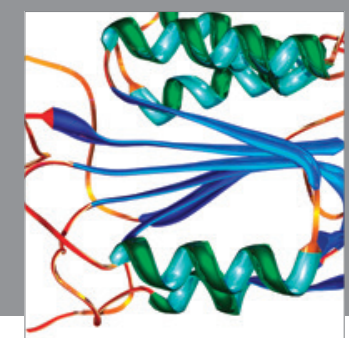

Disease Markers
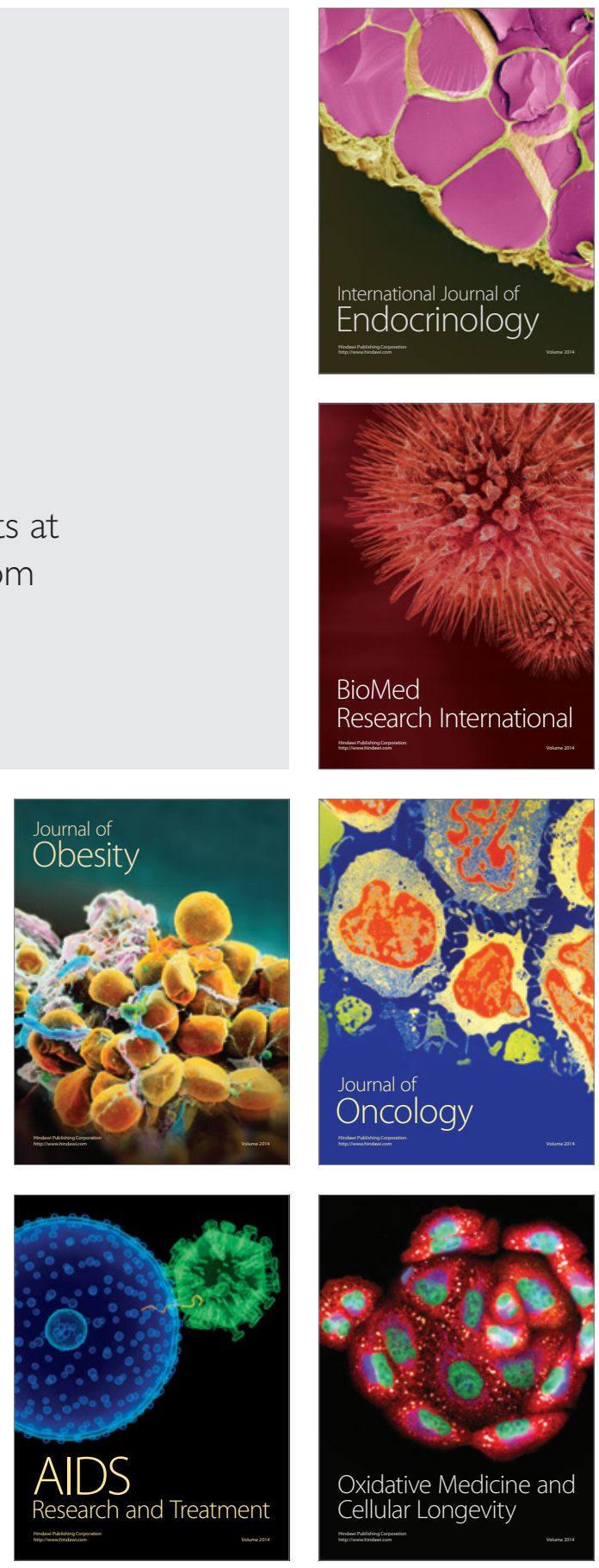